\title{
DISCLAIMER
}

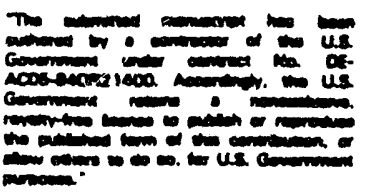

This report was prepared as an account of work sponsored by an agency of the United States Government. Neither the United States Government nor any agency theroof, nor any of their employees, makes any warranty, express or implied, or assumes any legal liability or responsibility for the accuracy, completeneas, or usefulness of any information, apparatus, product, or process discloced, or represents that its use would not infringe privately owned rights. Reference herein to hany specific commercial product, proceas, or service by trade name, trademark. manufacturer, or otherwise does not necessarily constitute or imply its endorsement, rocom. mendation, or favoring by the Unitod States Government or any agency thereof. The views and opinions of authors expresued herein do not necessarily state or reflect those of the United States Government or any agency thereof.

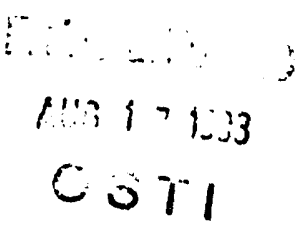

\section{OPERATION OF A TEST BED AXIALGAP BRUSHIIESS DC ROTOR WITH A SUPERCONDUCTING STATOR}

J. W. McKeever, C. W. Śohns, S. W. Schwenterly, R. W. Young, Sr., V. W. Campbell, M. H. Hickey, and G. W. Ott

Oak Ridge National Laboratory*

Oak Ridge, Tennessee

J. M. Bailey

The University of Tennessee

Knoxville, Tennessee

\begin{abstract}
A variable-speed axial-gap motor with a stator consisting of four liquid helium cooled superconducting electromagnets (two pole pairs) was built ${ }^{2}$ and proof tested up to $608 \mathrm{rpm}$ in November $1990^{2}$ as a tool for joint industry-laboratory evaluation of coils fabricated from high-temperature oxide superconductors. A second rotor was fabricated with improved material, winding configuration, and wire type, and the drive system was modified to eliminate current spiking. The modified motor was characterized to design speed, $188 \mathrm{rad} / \mathrm{s}(1800 \mathrm{rpm})$, to acquire a performance baseline for future comparison with that o high-temperature superconducting (HTS) wire. As it becomes commercially available, ITS wire will replace the low-temperature electromagnet wire in a stator modified to control wire temperatures between $4 \mathrm{~K}$ and $77 \mathrm{~K}$

Measurements of the superconducting electromagnetic field and locked rotor torque as functions of cryocurrent and de current through two phases of the rotor, respectively, provided data to estimate power that could be developed by the rotor. Back emf and parasitic mechanical and electromagnetic drag torques were measured as functions of angular velocity to calculate actual rotor power developed and to quantify at design speed confice the motor's efficiency. A detailed measurement of motor power at the 33-A maximumed the developed power equation. When subsequently operated the load.

In a tinal test, the cryostat was operated at $2500 \mathrm{~A}, 200 \mathrm{~A}$ below its critical current. At rotor design current of $60 \mathrm{~A}$ and $2500 \mathrm{~A}$ stator current, the extrapolated reveloped power would be $44.2 \mathrm{~kW}(59.2 \mathrm{hp})$ with $94 \%$ efficiency.
\end{abstract}

"Managed by Martin Marietta Energy Systems, Inc, under contract DE-AC05-84OR21400 with the U.S. Department of Energy.

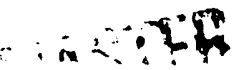




\section{INTRODUCTION}

The discovery of ceramic oxide superconductors with transition temperatures as high as $133 \mathrm{~K}^{3}$ has stimulated increased interest and anticipation in the electric equipment industry. American companies are working with the Department of Energy (DOE) laboratories to commercialize long lengths of HTS wire for electric pusver applications. Companies are working to develop superconducting motors in which the HTS wire may be used. In the spring of 1993, Emerson. Electric and the University of Houston 4 produced a 19-W (0.03-hp) axial-gap superconducting motor that useci a rotor with ingots of $\mathrm{Y}-\mathrm{Ba}-\mathrm{Cu}-\mathrm{O}$ in which the magnetic field had been trapped. Shortly after, Reliance Electric Co. announced that it had operated a 1.5-kW (2-hp) radial-gap motor.s Its 300-m flexible HTS field coils had been made by American Superconductor Corp.

Once the HTS wire is commercially available, there is great value in demonstrating its use in a motor that can deliver 37 to $75 \mathrm{~kW}$ (50 to $100 \mathrm{hp}$ ). The demonstration would prove the wire in an environment of torque pulses, fluctuating fields, and mechanical vibrations, typical of what it will see when in commercial or industrial operation. The demonstration would further expose potential design problems related to parasitic drags, cryostat design, drive inverter performance, inherently low inductance, flux focusing, and system operation.

\section{BACKGROUND}

A study of potential applications of high-temperature superconductors for electric energy, which was sponsored by DOE and the Electric Power Research Institute (EPRI), provided findings that inspired a proposal to build an axial-gap superconducting motor as a test bed for evaluating HTS wire when it became commercially available. The motor configuration reversed the role of the stator and armature from that used in earlier permanent-magnet, axial-gap configurations ${ }^{7,8}$ developed at the Oak Ridge National Laboratory (ORNL). The proposal led to a project which began in 1988 to develop and test such a motor in the desired range. The first project team members were drawn from the Applied Technology Division, Fusion Energy Division, Engineering Techoology Division, and Energy Division of ORNL and from the University of Tennessee. The motor and its components were assembled in what is called the Superconducting Motor Research Facility (SMRF). This is a national facility available not only to test HTS wire, but also to do motor, power electronics, and motor drive research.

The test bed motor consists of eight modules: (1) the stator is a cryostat which houses two pairs of superconducting electromagnets at liquid helium temperatures; (2) a 3000-A, 12-Vdc solid-state Model 06-700664.0007 ENG, Robicon Corp. power supply with its computer drive bypassed for manual operation provides power to the cryomagnets; (3) a split shaft rotor mounted on 5.1-cm (2-in.) and 6.0-cm (2 3/16-in.) diam Dodge pillow block bearings develops the motor's power; (4) two 19-kW power inverters phase locked to the rotor with an optical commutator and conniceted in parailiel provide an adjustable-speed drive to deliver up to $38 \mathrm{~kW}$ (51 hp) to the rotor; (5) a shaft with a 112-tooth gear mounted on two 3.8-cm (1 1/2-in.) diam Morris pillow block bearings transmits generated power to the load; (6) an S. Himmelstein and Co. (SHC) MCRT 9-02T (6-3) noncontact torquemeter connected through flex couplings on one end to the split shaft rotor and on the other to the gear shaft accurately measures the parasitic torques or drive torques; (7) an SHC Model 32 power instrument that measures strains and frequency signals from the torque meter at high speeds digitally displays values of torque, angular velocity, and power in engineering units; and (8) a 
Kahn Model 101-080 hydraulic absorption unit serves as the load and its 34-tooth gear is belt driven by the 112-tooth gear. A schematic of the superconducting motor is shown in Fig. 1.

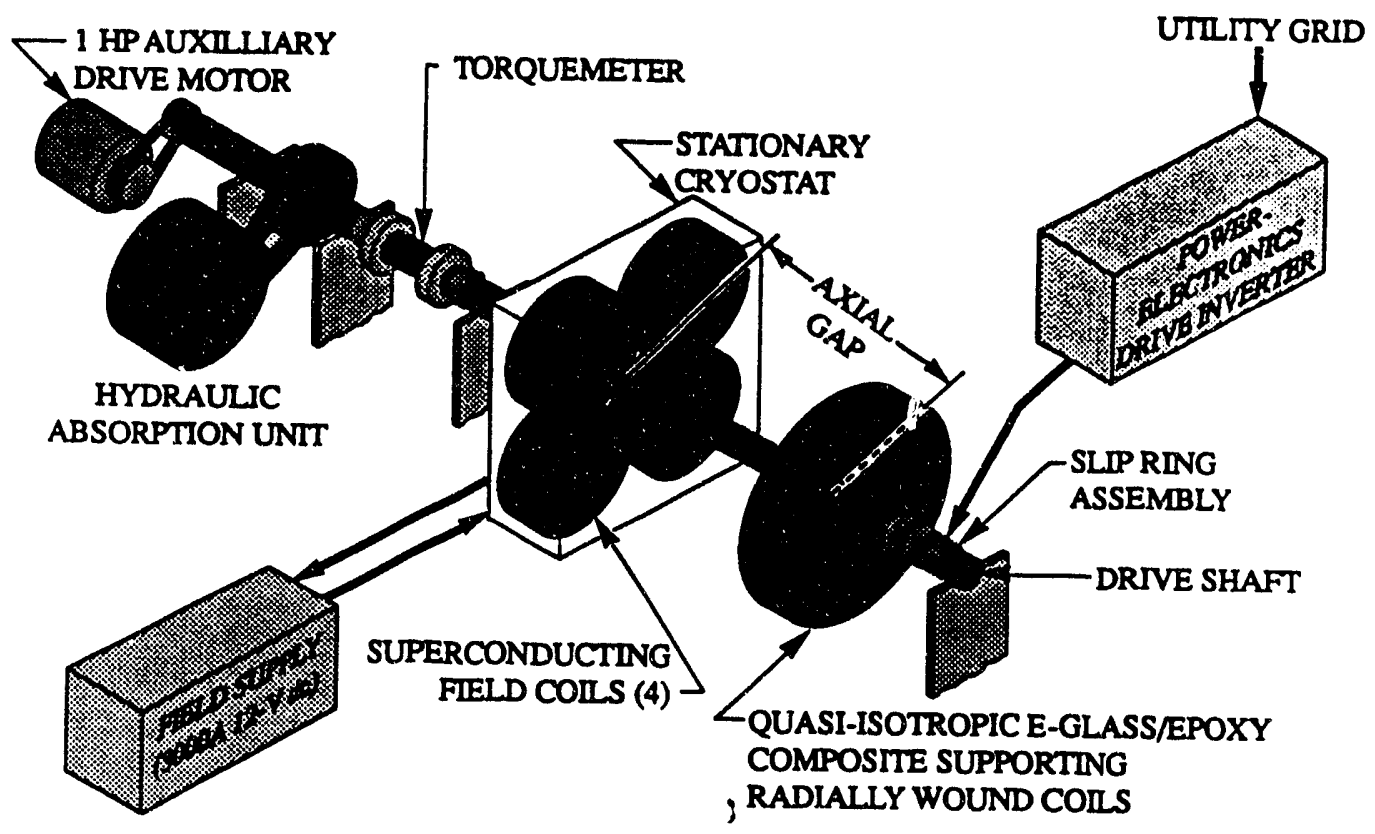

Fig. 1. Axial-gap superconducting motor.

A team was formed, and with funding from DOE Superconducting Technology Program, the modifications were completed, the system was reassembled, and on September 27, 1992, the motor characterization testing was completed.

\section{SUPERCONDUCTING CRYOSTAT}

The superconducting motor stator ${ }^{1}$ is the heart of the test bed motor. From inside out it comprises the coils, the coil assembly, the coil case, a copper heat shield, and the vacuum chamber's jacket. Details are presented in Ref. 1.

\section{ARMATURE MODIFICATIONS}

Four improvements were incorporated in the second rotor based on experience and information gained from the initial proof test. First, the rotor winding configuration was changed to eliminate circulating currents. Second, the copper Litz wire was replaced with 7-stranded 19-gage wire to facilitate handling and to minimize eddy current losses at design conditions. Third, the body of Rotor 2 was fabricated from a quasi-isotropic layup of B-staged E-glass cloth to replace the commercial G-11 material used in Rotor 1 , thereby producing a rotor capable of higher speeds and enabling finite element modeling of the operating rotor. 
Large circulating currents, which hindered the first proof test, were eliminated from Rotor 2 by connecting the four coils in series in each of the four parallel paths of the three phases. The electrical leads from each quadrant were brought through the rotor in 24 holes. half on the inner edge of the inner channel and half on the outer edge shown in the cross section of Fig. 2. The wires were crimped to eye lugs and secured with copper bolts to anchors equiangularly spaced on a $15.7-\mathrm{cm}(6.2-\mathrm{in}$.) diam bolt circle in the housing. Bus wifes were used to connect the coils in the proper 3-phase "wye" configuration.

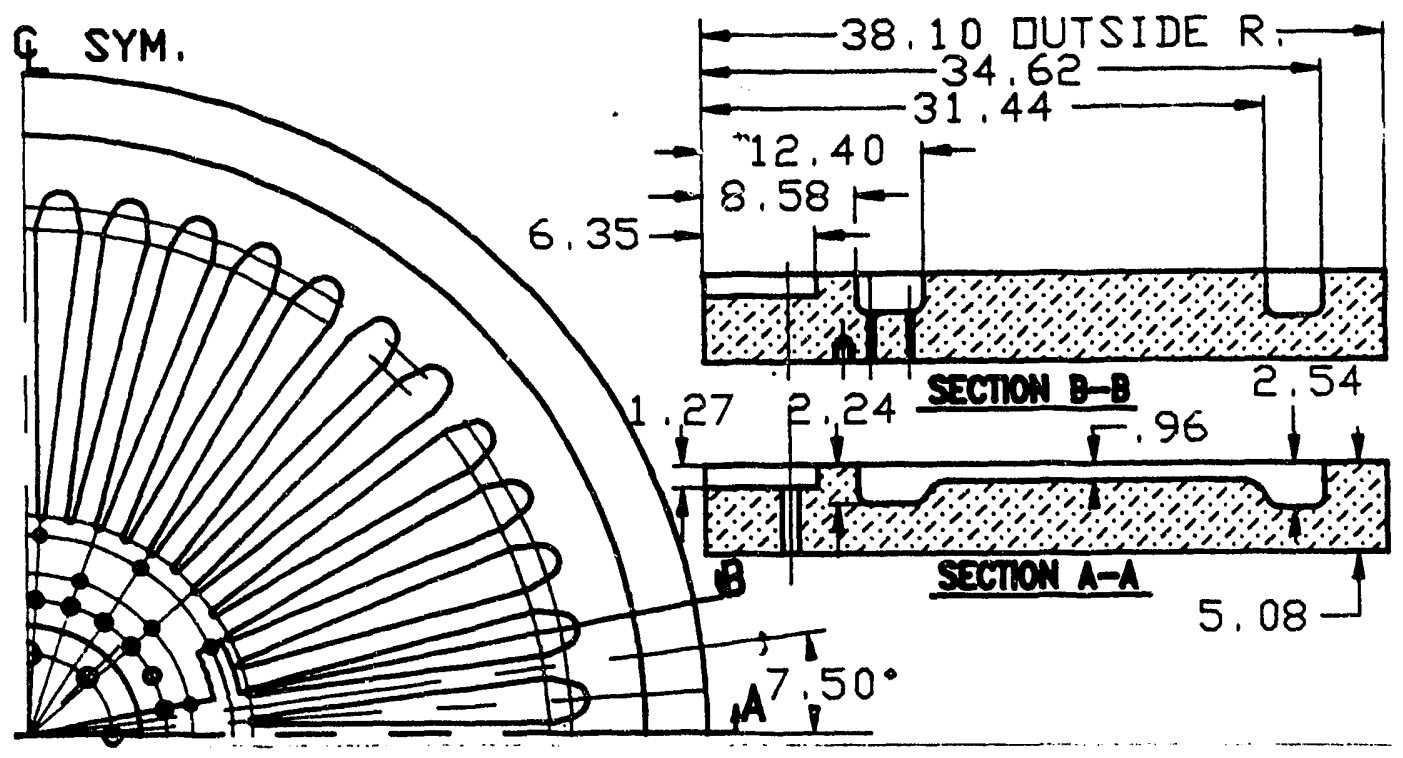

Fig. 2. Housing for SMRF Rotor 2.

Since the motor characterization necessitated operation at $188 \mathrm{rad} / \mathrm{s}(1800 \mathrm{rpm})$, safety considerations demanded an improved stress analysis. Rotor 1 had been fabricated from commercial G-11 material which contained a filier to reduce moduli to National Electrical Manufacturers Association values thereby reducing costs. Furthermore, its elastic properties were not isotropic making finite element analysis less certain. The solution was to procure a quasi-isotropic layup $\left[0^{\circ},+45^{\circ},-45^{\circ}, 90^{\circ}\right]$ of G-11 $\mathrm{CR}$ from Spaulding Composites $\mathrm{Co}$. for the rotor body. Improved quality of the quasiisotropic material, which had no filler, appeared as an increase in Young's modulus from 16 to $19 \mathrm{GPa}$ ( 2.3 and $2.8 \mathrm{msi}$ ) to a single value of $24 \mathrm{GPa}$ ( $3.5 \mathrm{msi}$ ), an increase in the glass volume fraction from 0.40 to 0.56 , and an increase in tensile strength from 240 and $280 \mathrm{MPa}$ (35 and $40 \mathrm{ksi}$ ) to $320 \mathrm{MPa}$ (46 ksi). The quasi-isotropic material was machined as shown in Fig. 2 using a numerical controlled lathe with somie hand touchup. The coils were wound in the slots and vacuum potted using DER 334 epoxy and $48 \mathrm{phr}$ Genamid 151 hardener. Ancimide 501 hardener, which was used to pot Rotor 1, could not be used to pot Rotor 2 because it formed a stable foam that made it unusable.

After the coils were vacuum potted, the flanges, which had been welded to the ends of the split shafts, were installed with two opposing stainless steel dowel pins and six Grade 8 bolts equiangularly spaced on a $9.5-\mathrm{cm}(3.75-\mathrm{in}$.) diam bo!t circle. The bolts were torqued to their recommended values of $67.8 \mathrm{~N}-\mathrm{m}(50 \mathrm{ft}-\mathrm{lb})$ after it was determined that the load would not crush the G-11 CR material. The rotor assembly 
was dynamically couple balanced in a balance machine on soft mounts. The mounts were positioned to simulate both test bed bearings. A hand grinder was used to remove material from the outside corners of the $5.08-\mathrm{cm}$ (2-in.) thick disk until the runout at the mounts was less than $0.01 \mathrm{~mm}(0.0004 \mathrm{in}$.).

\section{DRIVE SYSTEM}

A versatile control and drive system was modified to drive the SMRF test bed motor. Its parallel power inverters, which can each deliver $25 \mathrm{~kW}(33 \mathrm{hp})$ at $40 \mathrm{~A}$, were fused to limit power delivery to $19 \mathrm{~kW}(25 \mathrm{hp})$ at $30 \mathrm{~A}$. The control system incorporates an optical commutator, an EPM 5032 programmable device, and a fiberoptic line driver. The optical commutator provides information to phase lock the waveform of the inverter output to the motor. The optical commutator was used because of its stability in the presence of high power and high magnetic fields and the ease with which it may alter the phase angle. The EPM 5032 programmable device was incorporated in the control system to allow rapid, inexpensive circuit changes as needed. Unfortunately, during the motor characterization, one of the EPMs stopped working, which cut the available power in half. The maximum power developed during the motor characterization was $19 \mathrm{~kW}(26 \mathrm{hp})$. Inductors with $1 \mathrm{mH}$ total inductance were installed in each phase between the drive system and the motor to eliminate current spikes, which had tripped the inverter during the 1990 proof test.

\section{INSTRUMENTATION}

Several instruments were used in additionto those listed in the Background section. These include a Lecroy $9314 \mathrm{M}$ digital storage scope (DSS) and a Wavetech 5810A spectral analyzer. The digital scope was used to record and measure the total electrical power input to the motor during efficiency measurements. It provided a spectral analysis of the current showing that of the $23.6 \mathrm{~A}$ rms phase current only $22.5 \mathrm{~A} \mathrm{rms}$ was available to deliver power at the fundamental frequency. A schematic of the instrumentation is shown in Fig. 3. The Wavetech $5810 \mathrm{~A}$ was used to analyze output from an accelerometer attached to the pillow block closest to the slip rings to quantify the severity of test stand or rotor resonances that occur as the rotor is driven to speed.

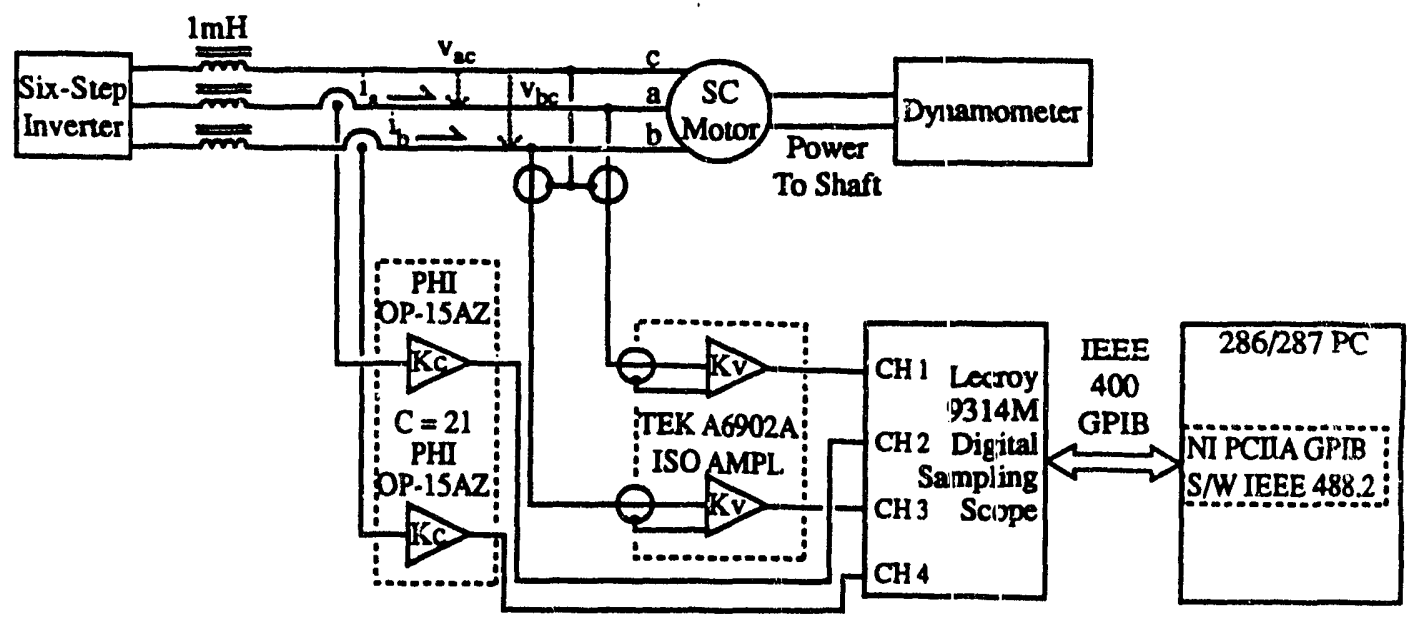

Fig. 3. Instrumentation for measurement of total electrical power input to SMRF motor. 
It was also used to analyze output from strain gages mounted in the cryostat during delivery of $15 \mathrm{~kW}(20 \mathrm{hp})$ to the hydraulic absorption load.

\section{MOTOR CHARACTERIZATION PROCEDURE}

Motor characterization was conducted in three phases. During the first phase, the rotor shaft was driven by a $0.75-\mathrm{kW}(1-\mathrm{hp})$ motor to verify that the rotor was mechanically sound at design speed, to locate and measure the amplitude of resonances detected during driveup by an accelerometer on the pillow block closest to the slip rings, to measure the back emf generated by the rotor as a function of angular velocity, and to measure parasitic torques. Back emf and torque were again measured as a function of angular velocity with the drag from current circulating in parallel paths of the coils eliminated by electrically opening each coil at its line voltage connection.

During the second test phase, the field strength on the axis of one superconducting magnet was measured with a Hall probe as a function of stator current at the face of the cryostat and at the side of the rotor farthest from the cryostat. With the rotor fixed, torque was measured as a function of direct current to the rotor. In the final test of the second phase, which occurred at the end of the test plan, the cryostat was successfully operated at $2500 \mathrm{~A}, 200 \mathrm{~A}$ below its critical current.

The third test phase provided data at design speed. The first step was a detailed measurement of power to the motor to evaluate the equation for power developed by the rotor. The second step was operation of the motor at maximum available rotor current. At the beginning of the third phase, half of the inverter failed, limiting the rotor current to about $33 \mathrm{~A}$.

\section{TEST RESULTS}

3

As the rotor was accelerated to $188 \mathrm{rad} / \mathrm{s}(1800 \mathrm{rpm})$ during the mechanical verification, angular velocity was increased slowly through rescnances to see if their magnitudes were sufficient to cause trouble during motor operation. None were found.

Measured parasitic torques are shown in Fig. 4 as a function of angular velocity at several stator currents. The area under the curve is proportional to the power consumed. With zero stator current the losses are mechanical. The calculated bearing loss was $0.68 \mathrm{n}-\mathrm{m}$ (6 in.-lb) and does not change with angular velocity. The region between the $0.68 \mathrm{n}-\mathrm{m}$ line and the line with zero stator current is the power consumed by windage and pumping. The region above the line with zero stator current is the power consumed by eddy currents in the coils, by currents circulating through parallel paths in each phase, by currents induced in the squirrel cage formed by the rotor flanges, bolts, and dowel pins, and by eddy currents induced in the two flanges. At $188 \mathrm{rad} / \mathrm{s}$, the total eddy and circulation drag from Fig. 4 is $2.2 \mathrm{~kW}(3.0 \mathrm{hp})$. Power Consumption by the squirrel cage at $188 \mathrm{rad} / \mathrm{s}$ was estimated to be $1.0 \mathrm{~kW}(1.3 \mathrm{hp})$. When the currents circulating through parallel paths in each phase were stopped by opening the circuits, drag torque was reduced by $0.2 \mathrm{~kW}(0.3 \mathrm{hp})$ with a standard deviation of $0.04 \mathrm{~kW}$. Values from a scope trace of the differential emf generated across two parallel paths in one winding were used to estimate a power consumption of $0.1 \mathrm{~kW}(0.1 \mathrm{hp})$. This calculation using the scope trace, although crude, exhibits orderof-magnitude agreement with the torque drag measurements. Eddy current losses in the rotor coils was calculated to be $0.2 \mathrm{~kW}(0.2 \mathrm{hp})$. The remaining drag from eddy currents induced in the two flanges is $0.9 \mathrm{~kW}(1.2 \mathrm{hp})$. 


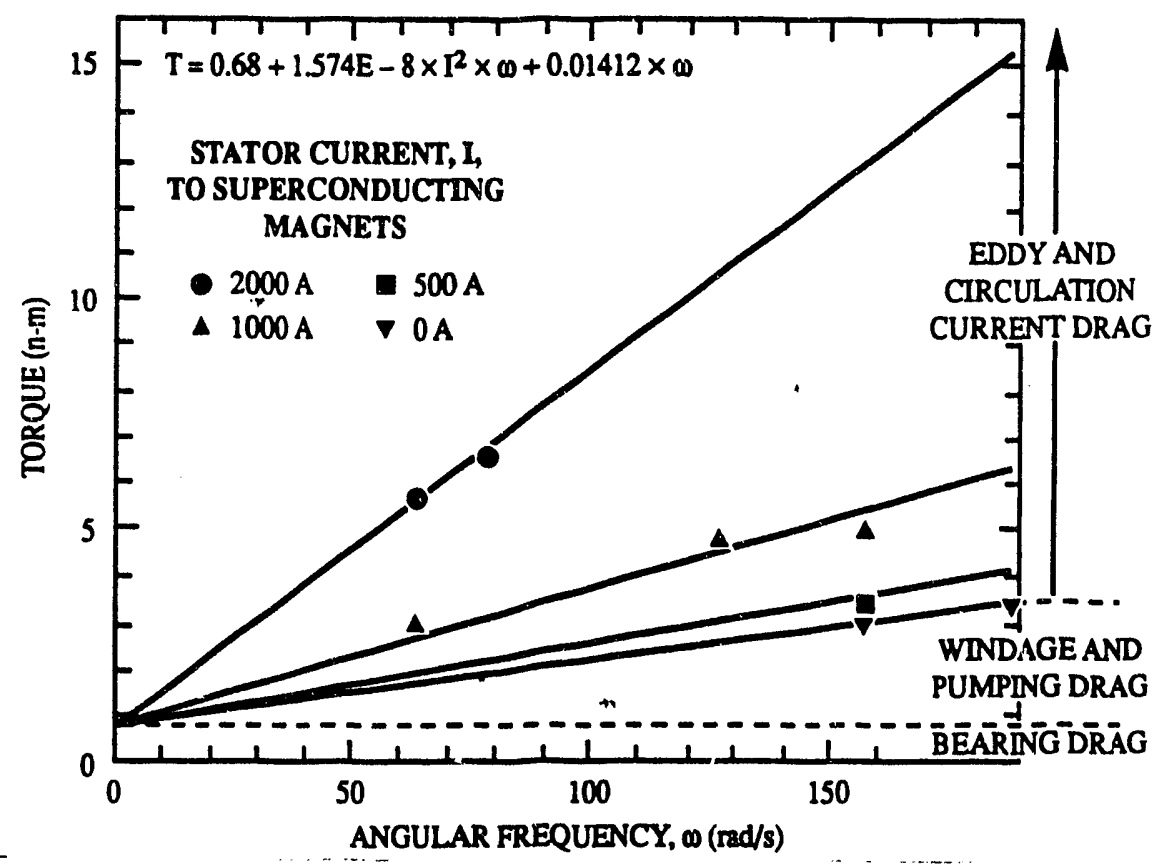

Fig. 4. Parasitic torque in Rotor 2.

A Hall probe was used to measure the magnetic field on the axis of the electromagnet at the face of the cryostat and at the side of the rotor opposite the coils. The equations are $B_{\text {tace }}=0.001023 \times I$ and $B_{\text {beck }}=0.0003615 \times I$, respectively. I is the cryomagnet current in amps and the standard deviation per point is 0.02 Tesla.

Locked rotor torque was measured as a function of dc current to the rotor at 1000 and $2000 \mathrm{~A}$ through the stator. Current went in one phase and out another with the third phase inactive. The torque equation is $\mathrm{T}=0.001307 \times \mathrm{I} \times \mathrm{i}$. I is the cryomagnet current and $i$ is the rotor current. The standarci deviation per point of the data over the full torque range anticipated for this rotor is $0.77 \mathrm{n}-\mathrm{m}$ (6.8 in.-lb). The relation between the slopes of the back emf-angular velocity curve and the locked rotor torque-current

curve for square current waves is $b_{\text {end }} b_{\text {longer }}=\pi \sqrt{2} / 6$. The back imf is shown in Fig. 5 as a function of angular velocity. The dashed lines show the back emf predicted from the locked rotor torque curves. The difference represents deviation of the current from true square waves. The agreement is within $7 \%$.

Three cases of power consumption and distribution in the SMRF motor are important. Two are real and one is possible. The first case was the characterization measurement of Rotor 2 for which $13.2 \mathrm{~kW}(17.7 \mathrm{hp})$ was developed and $10.8 \mathrm{~kW}$ $(14.5 \mathrm{hp})$ was delivered to the hydraulic absorption unit. This detailed energy measurement provided data used to determine how much power Rotor 2 could develop. The resulting equation for the developed power in watts is $P=1.72 \times B \times \omega \times i$, where $B$ is the field strength in Tesla at the rotor coil's midplane (1.8Z Tesla), $\omega$ is the angular velocity in rad/s, and $i$ is the rotor current in amps. The second case was a measurement of $15.3 \mathrm{~kW}$ power delivered to the load by the rotor with developed power calculat $d$ to be $18 \mathrm{~kW}$ at the maximum rotor current. Current was limited to $33 \mathrm{~A}$ because one inverter was inoperative. The hypothetical case is an estimate of the potential $44.2 \mathrm{~kW}$ of developed power at design conditions for delivery of $41.4 \mathrm{~kW}$ to the load at $94 \%$ efficiency. These calculations are based on results from this motor characterization with the squirrel cage bolts insulated to eliminate $1.3 \mathrm{~kW}$ of loss. 


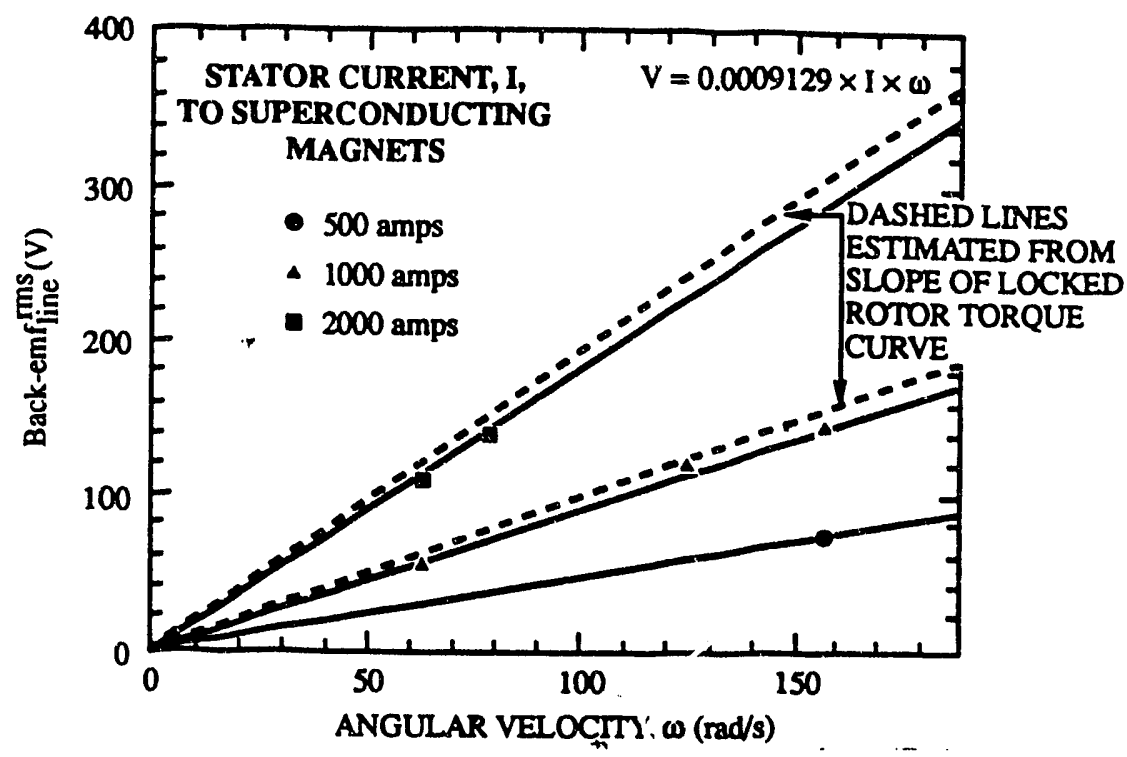

Fig. 5. Back emf generated by Rotor 2.

\section{CONCLUSIONS}

1. A test bed axial-gap motor with a stator whose electromagnets are lowtemperature superconductors has provided a baseline for comparison with subsequent operation with a stator whose electromagnets are high-temperature superconductors.

2. The rotor developed $18 \mathrm{~kW}(24 \mathrm{hp})$ at a rotor current of $33 \mathrm{~A}$ and a stator current of $2000 \mathrm{~A}$ and delivered $15.3 \mathrm{~kW}(20.5 \mathrm{hp})$ to a load.

3. Measurements of parasitic mechanical and EM drags have provided information suggesting design changes for improving efficiency.

4. A detailed efficiency measurement and successful operation of the stator at $2500 \mathrm{~A}$ indicated that the test bed motor is capable of developing $44.2 \mathrm{~kW}(59.2 \mathrm{hp})$ at a design current of $60 \mathrm{~A}$ and a stator current of $2500 \mathrm{~A}$. Power delivery to a load is expected to be $41.4 \mathrm{~kW}$ (55 hp).

\section{REFERENCES}

1. S.W. Schwenterly, J.N. Luton, J.W. Lue, W.J. Kenney, and M.S. Lubell, and Testing of a Four-pole Superconducting Motor Stator," Advances in Cyogenic Enginecring, Vol. 37A, p. 473-479 (1991).

2. R.A. Hawsey, W.K. Kahl, S.W. Schwenterly, J.M. Bailey, C.W. Sohns, J.N. Luton, B.W. McConnell, V.W. Campbell, "Analysis and Performance of an Axial-Gap Superconducting Motor," IEEE Trans on Magnetics, Vol. 27, No. 2, (1991).

3. A. Schilling et al., "HgBaCaCuO with Transition Temp at $133 \mathrm{~K}$," Nature, Vol. 363, (May 6, 1993).

4. C. Gillespie ed., "One Small Step: An SC Motor is Tested Successfully," Superconducting Industry,
(Spring 1993). 5. P.K Tompkins, "Reliance Electric Announces Progress on Superconducting Motors," News Release,
No. 93-8, (April 26, 1993).

6. S.J. Dale, S.M. Wolf, and T.R. Schneider, "Energy Applications of High-Temperature Superconductivity-Extended Summary Report," Electric Power Research Institute, ER-6682,
Vol. 1, (February 1990).

7. J.M. Bailey et al., "A Self-Starting, Axial-Gap Permanent Magnet Motor and Adjustable-Speed Drive," Proc. IEEE Southeastem Conference, 718-522 (1988).

8. R.A Hawsey et al., "High Power Density Generator Concepts for Aerospace Electric Power," Proc. of the 24th Intersociety Energy Conversion Engineering Conference, Washington D.C., pp. 1109.
1114 (1989). 


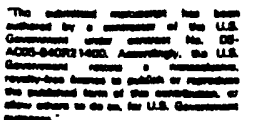

ming

\section{a. $-\cdots$, \\ f'? $1,1,33$ \\ C}

OPERATION OF A TEST BED AXIALGGAP BRUSHLESS DC ROTOR WTH A SUPERCONDUCTING STATOR

J. W. McKeever, C. W. Sohns, S. W. Schwenterly, R. W. Young, Sr., V. W. Campbell, M. H. Hickey, and G. W. Ott

Oak Ridge National Laboratory*

Oak Ridge, Tennestee

J. M. Bailey

The University of Tennessee

Knoxville, Temnessee

\section{ABSTRACT}

A variabie-speed arial-gap motor with a stator consisting of four liquid helium cooled superconducting electromagnets (two pole pairs) was built' and proof tested up to $608 \mathrm{rpm}$ in November $1990^{2}$ as a tool for joint industry-laboratory evaluation of coils fabricated from high-temperature oxide superconductors. A second rotor was fabricated with improved material, winding configuration, and wire type, and the drive system was modified to eliminate current spiking. The modified motor was characterized to design speed, $188 \mathrm{rad} / \mathrm{s}$ (1800 rpm)s to acquire a performance baseline for future comparison with that of high-temperature superconducting (HTS) wire. As it becomes commencially available, HTS wire will replace the low-iemperature electromagnet wire in atator modified to control wire temperatures between $4 \mathrm{~K}$ and $77 \mathrm{~K}$

Measurements of the superconducting electromsenetic field and locked rotor torque as functions of cyocurrent and de current through two phases of the rotor, respectively, provided data to estimate power that could be developed by the rotor. Back emf and parasitic mechanical and electromagnetic drag torques were measured as functions of angular velocity to calculate actual rotor power developed and to quantify losses, which reduce the motor's efficiency. A detailed mearurement of motor power at design speed confinmed the developed power equation. When subsequently operated at the 33-A maximum available rotor current, the motor delivered $15.3 \mathrm{~kW}(20.5 \mathrm{hp})$ to

In a final test, the cryostat was operated at $2500 \mathrm{~A}, 200 \mathrm{~A}$ below its critical current. At rotor dexign current of $60 \mathrm{~A}$ and $2500 \mathrm{~A}$ stator curreat, the extrapolated developed power would be $44.2 \mathrm{~kW}$ ( $59.2 \mathrm{hp})$ with $94 \%$ efficiency.

- Managed by Marin Marietu Eoergy Syatems, ince, under contract DE-ACO5-84OR21400 with the U.S. Department of Enersy. 


\section{INTRODUCTION}

The discovery of ceramic oxide superconductors with transition temperatures as high as $133 \mathrm{~K}^{3}$ has stimulated increased interest and anticipation in the electric equipment industry. American companies are working with the Department of Energy (DOE) laboratories to commercialize long lengths of HTS wire for electric power applications. Companies are working to develop superconducting motors in which the HTS wire may be used. In the spring of 1993, Emerson Electric and the University of Houstor: produced a 19-W (0.03-hp) axial-gap superconducting motor that used a rotor with ingots of $\mathrm{Y}-\mathrm{Ba}-\mathrm{Cu}-\mathrm{O}$ in which the magnetic field had been trapped. Shortly after, Reliance Electric Co. announced that it had operated a 1.5-kW (2-hp) radial-gap motor. Its 300-m flexible HTS field coils had been made by American Superconductor Corp.

Once the HTS wire is commercially available, there is great value in demonstrating its use in a motor that can deliver 37 to $75 \mathrm{~kW}$ (50 to $100 \mathrm{hp}$ ). The demonstration would prove the wire in an environment of torque pulses, fluctuating fields, and mechanical vibrations, typical of what it will see when in commercial or industrial operation. The demonstration would further expose potential design problems related to parasitic drags, cryostat design, drive inverter performance, inherently low inductance, flux focusing, and system operation.

\section{BACKGROUND}

A study of potential applications of high-temperature superconductors for electric energy, which was sponsored by DOE and the Electric Power Research Institute (EPRI), ${ }^{6}$ provided findings that inspired a proposal to build an axial-gap superconducting motor as a test bed for evaluating HTS wire when it became commercially available. The motor configuration reversed the role of the stator and armature from that used in earlier permanent-magnet, axial-gap configurations ${ }^{7,8}$ developed at the Oak Ridge National Laboratory (ORNL). The proposal led to a project which began in 1988 to develop and test,such a motor in the desired range. The first project team members were drawn from the Applied Technology Division, Fusion Energy Division, Engineering Technology Division, and Energy Division of ORNL and from the University of Tennessee. The motor and its components were assembled in what is called the Superconducting Motor Research Facility (SMRF). This is a national facility available not only to test 'HTS wire, but also to do motor, power electronics, and motor drive research.

The test bed motor consists of eight modules: (1) the stator is a cryostat which houses two pairs of superconducting electromagnets at liquid helium temperatures; (2) a 3000-A, 12-Vdc solid-state Model 06-700664.0007 ENG, Robicon Corp. power supply with its computer drive bypassed for manual operation provides power to the cryomagnets; (3) a split shaft rotor mounted on 5.1-cm (2-in.) and 6.0-cm (2 3/16-in.) diam Dodge pillow block bearings develops the motor's power; (4) two 19-kW power inverters phase locked to the rotor with an optical commutator and connected in parailel provide an adjustable-speed drive to deliver up to $38 \mathrm{~kW}$ ( $51 \mathrm{hp}$ ) to the rotor; (5) a shaft with a 112-tooth gear mounted on two 3.8-cm (1 1/2-in.) diam Morris pillow block bearings transmits generated power to the load; (6) an S. Himmelstein and Co. (SHC) MCRT 9-02T (6-3) noncontact torquemeter connected through flex couplings on one end to the split shaft rotor and on the other to the gear shaft accurately measures the parasitic torques or drive torques; (7) an SHC Model 32 power instrument that measures strains and frequency signals from the torque meter at high speeds digitally displays values of torque, angular velocity, and power in engineering units; and (8) a 
Kahn Model 101-080 hydraulic absorption unit serves as the load and its 34-tooth gear is belt driven by the 112-tooth gear. A schematic of the superconducting motor is shown in Fig. 1.

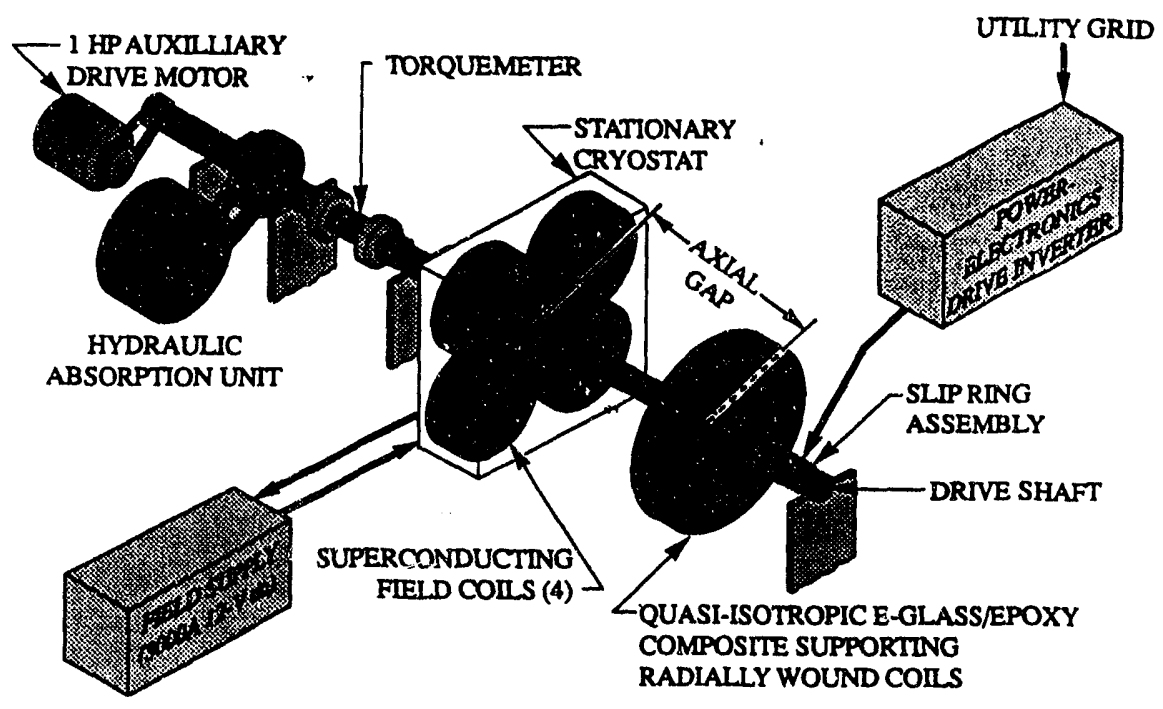

Fig. 1. Axial-gap superconducting motor.

A team was formed, and with funding from DOE Superconducting Technology Program, the modifications were completed, the system was reassembled, and on September 27, 1992, the motor characterization testing was completed.

\section{SUPERCONDUCTING CRYOSTAT}

The superconducting motor stator ${ }^{1}$ is the heart of the test bed motor. From inside out it comprises the coils, the coil assembly, the coil case, a copper heat shield, and the vacuum chamber's jacket. Details are presented in Ref. 1.

\section{ARMATURE MODIFICATIONS}

Four improvements were incorporated in the second rotor based on experience and information gained from the initial proof test. First, the rotor winding configuration was changed to eliminate circulating currents. Second, the copper Litz wire was replaced with 7-stranded 19-gage wire to facilitate handling and to minimize eddy current losses at design conditions. Third, the body of Rotor 2 was fabricated from a quasi-isotropic layup of B-staged E-glass cloth to replace the commercial G-11 material used in Rotor 1 , thereby producing a rotor capable of higher speeds and enabling finite element modeling of the operating rotor. 
Large circulating currents, which hindered the first proof test, were eliminated from Rotor 2 by connecting the four coils in series in each of the four parallel paths of the three phases. The electrical leads from each quadrant were brought through the rotor in 24 holes, half on the inner edge of the inner channel and half on the outer edge shown in the cross section of Fig. 2. The wires were crimped to eye lugs and secured with copper bolts to anchors equiangularly spaced on a $15.7-\mathrm{cm}(6.2-\mathrm{in}$.) diam bolt circle in the housing. Bus wires were used to connect the coils in the proper 3-phase "wye" configuration.

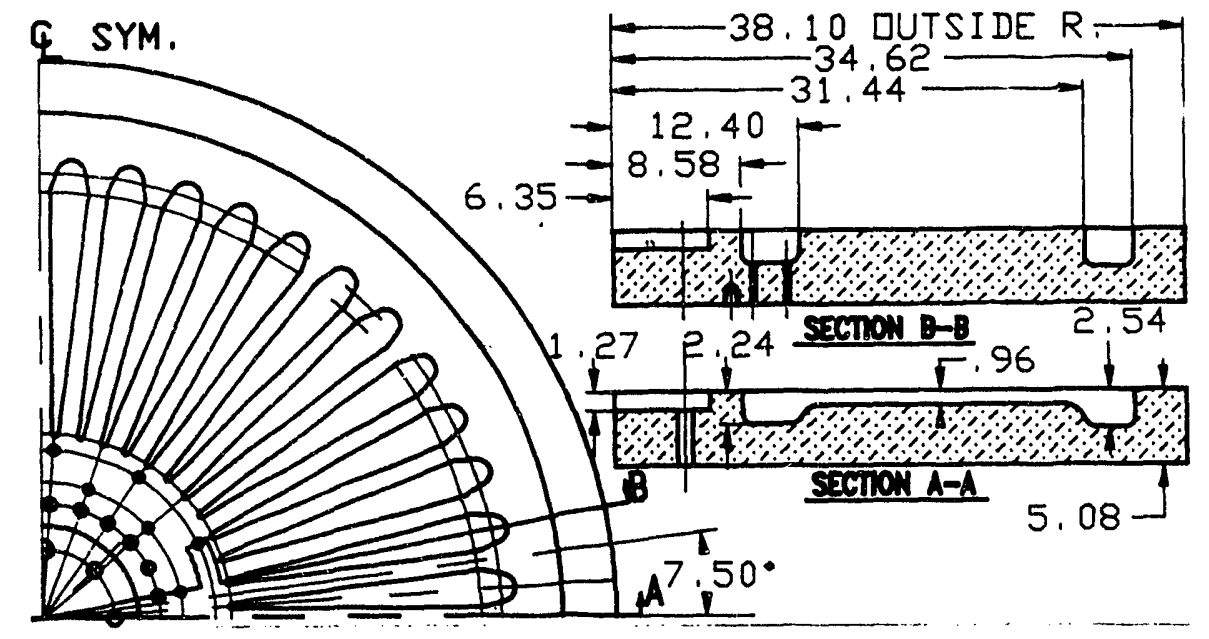

Fig. 2 Housing for SMARF Rotor 2.

Since the motor characterization necessitated operation at $188 \mathrm{rad} / \mathrm{s}(1800 \mathrm{rpm})$, safety considerations demanded an improved stress analysis. Rotor 1 had been fabricated from commercial G-11 material which contained a filler to reduce moduli to National Electrical Manufacturers Association values thereby reducing costs. Furthermore, its elastic properties were not isotropic making finite element analysis less certain. The solution was to procure a quasi-isotropic layup $\left[0^{\circ},+45^{\circ},-45^{\circ}, 90^{\circ}\right]$ of $\mathrm{G}-11$ $\mathrm{CR}$ from Spaulding Composites Co. for the rotor body. Improved quality of the quasiisotropic material, which had no filler, appeared as an increase in Young's modulus from 16 to $19 \mathrm{GPa}$ ( 2.3 and $2.8 \mathrm{msi}$ ) to a single value of $24 \mathrm{GPa}$ ( $3.5 \mathrm{msi})$, an increase in the glass volume fraction from 0.40 to 0.56 , and an increase in tensile strength from 240 and $280 \mathrm{MPa}$ ( 35 and $40 \mathrm{ksi}$ ) to $320 \mathrm{MPa}$ (46 ksi). The quasi-isotropic material was machined as shown in Fig. 2 using a numerical controlled lathe with some hand touchup. The coils were wound in the slots and vacuum potted using DER 334 epoxy and 48 phr Genamid 151 hardener. Ancimide 501 hardener, which was used to pot Rotor 1 , could not be used to pot Rotor 2 because it formed a stable foam that made it unusable.

After the coils were vacuum potted, the flanges, which had been welded to the ends of the split shafts, were installed with two opposing stainless steel dowel pins and six Grade 8 bolts equiangularly spaced on a $9.5-\mathrm{cm}(3.75-\mathrm{in}$.) diam bolt circle. The bolts were torqued to their recommended values of $67.8 \mathrm{~N}-\mathrm{m}(50 \mathrm{ft}-\mathrm{lb})$ after it was determined that the load would not crush the G-11 CR material. The rotor assembly 
was dynamically couple balanced in a balance machine on soft mounts. The mounts were positioned to simulate both test bed bearings. A hand grinder was used to remove material from the outside corners of the $5.08-\mathrm{cm}(2-\mathrm{in}$.) thick disk until the runout at the mounts was less than $0.01 \mathrm{~mm}$ (0.0004 in.).

\section{DRIVE SYSTEM}

A versatile control and drive system was modified to drive the SMRF test bed motor. Its parallel power inverters, which can each deliver $25 \mathrm{~kW}$ (33 hp) at $40 \mathrm{~A}$, were fused to limit power delivery to $19 \mathrm{~kW}(25 \mathrm{hp})$ at $30 \mathrm{~A}$. The control system incorporates an optical commutator, an EPM 5032 programmable device, and a fiberoptic line driver. The optical commutator provides information to phase lock the waveform of the inverter output to the motor. The optical commutator was used because of its stability in the presence of high power and high magnetic fields and the ease with which it may alter the phase angle. The EPM 5032 programmable device was incorporated in the control system to allow rapid, inexpensive circuit changes as needed. Unfortunately, during the motor characterization, one of the EPMs stopped working, which cut the available power in half. The maximum power developed during the motor characterization was $19 \mathrm{~kW}(26 \mathrm{hp})$. Inductors with $1 \mathrm{mH}$ total inductance were installed in each phase between the drive system and the motor to eliminate current spikes, which had tripped the inverter during the 1990 proof test.

\section{INSTRUMENTATION}

Several instruments were used in addition to those listed in the Background section. These include a Lecroy $9314 \mathrm{M}$ digital storage scope (DSS) and a Wavetech 5810A spectral analyzer. The digital scope was used to record and measure the total electrical power input to the motor during efficiency measurements. It provided a spectral analysis of the current showing that of the $23.6 \mathrm{~A}$ rms phase current only $22.5 \mathrm{~A} \mathrm{rms}$ was available to deliver power at the fundamental frequency. A schematic of the instrumentation is shown in Fig. 3. The Wavetech 5810A was used to analyze output from an accelerometer attached to the pillow block closest to the slip rings to quantify the severity of test stand or rotor resonances that occur as the rotor is driven to speed.

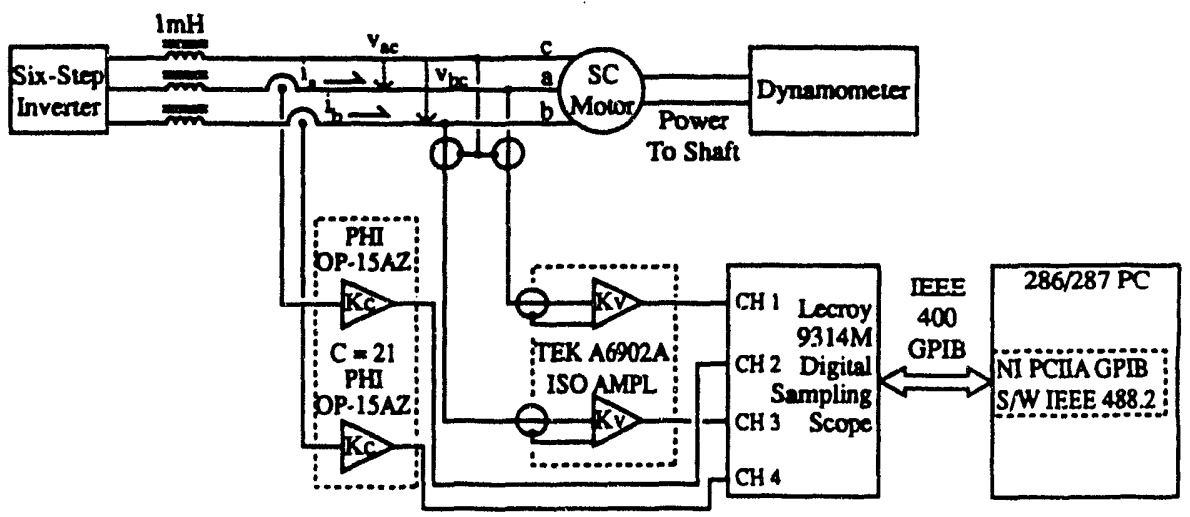

Fic. 3. Instrumentation for measurement of ofal electrical mous: anut a c apf moter 
It was also used to analyze output from strain gages mounted in the cryostat during delivery of $15 \mathrm{~kW}(20 \mathrm{hp})$ to the hydraulic absorption load.

\section{MOTOR CHARACTERIZATION PROCEDURE}

Motor characterization was conducted in three phases. During the first phase, the rotor shaft was driven by a $0.75-\mathrm{kW}$ (1-hp) motor to verify that the rotor was mechanically sound at derign speed, to locate and measure the amplitude of resonances detected during driveup by an accelerometer on the pillow block closest to the slip rings, to measure the back emf generated by the rotor as a function of angular velocity, and to measure parasitic torques. Back emf and torque were again measured as a function of angular velocity with the drag from current circulating in parallel paths of the coils eliminated by electrically opening each coil at its line voltage connection.

During the second test phase, the field strength on the axis of one superconducting magnet was measured with a Hall probe as a function of stator current at the face of the cryostat and at the side of the rotor farthest from the cryostat. With the rotor fixed, torque was measured as a function of direct current to the rotor. In the final test of the second phase, which occurred at the end of the test plan, the cryostat was successfully operated at $2500 \mathrm{~A}, 200 \mathrm{~A}$ below its critical current.

The third test phase provided data at design speed. The first step was a detailed measurement of power to the motor to evaluate the equation for power developed by the rotor. The second step was operation of the motor at maximum available rotor current. At the beginning of the third phase, half of the inverter failed, limiting the rotor current to about $33 \mathrm{~A}$.

\section{TEST RESULTS}

As the rotor was accelerated to $188 \mathrm{rad} / \mathrm{s}(1800 \mathrm{rpm})$ during the mechanical verification, angular velocity was increased slowly through resonances to see if their magnitudes were sufficient lo cause trouble during motor operation. None were found.

Measured parasitic torques are shown in Fig. 4 as a function of angular velocity at several stator currents. The area under the curve is proportional to the power consumed. With zero stator current the losses are mechanical. The calculated bearing loss was $0.68 \mathrm{n}-\mathrm{m}$ (6 in.-lb) and does not change with angular velocity. The region between 'he $0.68 \mathrm{n}-\mathrm{m}$ line and the line with zero stator current is the power consumed by windage and pumping. The region above the line with zero stator current is the power consumed by eddy currents in the coils, by currents circulating through parallel paths in each phase, by currents induced in the equitrel cage formed by the rotor anges, bolts, and dowel pins, and by eddy currents troduced in the two banges. As $188 \mathrm{radh}$, the cotal eddy and circulation drag trom Fis 4 b $22 \mathrm{~kW}$ (3.0 hp). Power

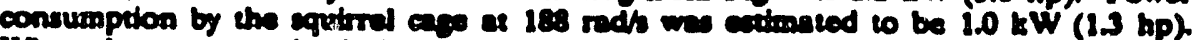

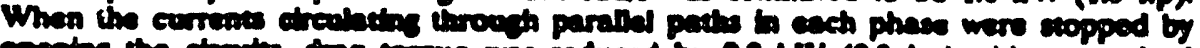

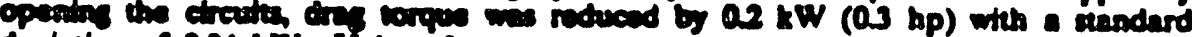

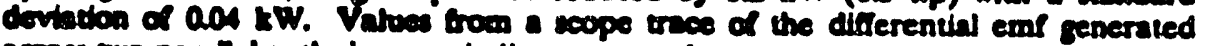
serose two paniliel patis ba cone winding were used to estimate a power consumption of $0.1 \mathrm{~kW}(0.1 \mathrm{bp})$. This calculation uxing the scope trece, although crude, exhibits orderof-magnitude agreement with the torque drag measurements. Eddy current losses in the rotor coils was calculated to be $0.2 \mathrm{~kW}(0.2 \mathrm{hp})$. The remaining drag from eddy currents induced in the two tlanges is $0.9 \mathrm{~kW}$ (1.2 hp). 


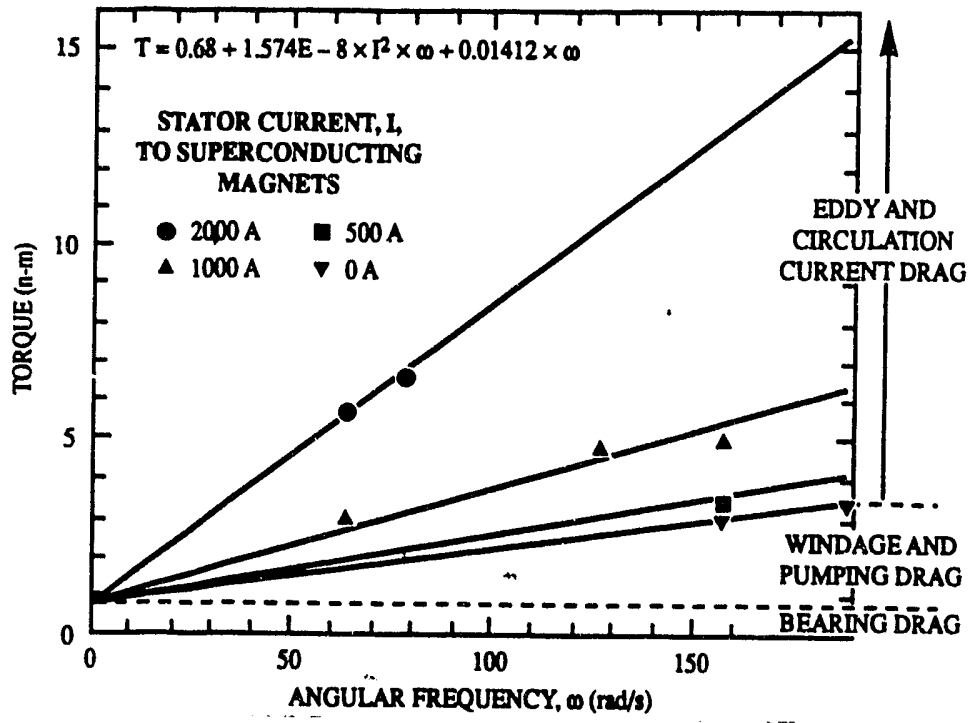

Fig. 4. Parasitic torque in Rotor 2.

A Hall probe was used to measure the magnetic field on the axis of the electromagnet at the face of the cryostat and at the side of the rotor opposite the coils. The equations are $B_{\text {woe }}=0.001023 \times I$ and $B_{\text {max }}=0.0003615 \times I$, respectively. I is the cryomagnet current in amps and the standard deviation per point is 0.02 Tesla.

Locked rotor torque was measured as a function of de current to the rotor at 1000 and $2000 \mathrm{~A}$ through the stator. Current wert in one phase and out another with the third phase inactive. The torque equation is $\mathrm{T}=0.001307 \times \mathrm{I} \times \mathrm{i}$. I is the cryomagnet current and $i$ is the rotor current. The standard deviation per point of the data over the full torque range anticipated for this rotor is $0.77 \mathrm{n}-\mathrm{m}(6.8 \mathrm{in} . \mathrm{lb})$. The relation between the slopes of the back emf-angular velocity curve and the locked rotor torque-current

curve for square current waves is $b_{\text {ean }} / b_{\text {monqu }}=\pi \sqrt{2 / 6}$. The back emf is shown in Fig. 5 as a function of angular velocity. The dashed lines show the back emf predicted from the locked rotor torque curves. The difference represents deviation of the current from true square waves. The agreement is within $7 \%$.

Three cases of power consumption and distribution in the SMRF motor are important. Two are real and one is possible. The first case was the characterization measurement of Rotor 2 for which $13.2 \mathrm{~kW}(17.7 \mathrm{hp})$ was developed and $10.8 \mathrm{~kW}$ $(14.5 \mathrm{hp})$ was delivered to the hydraulic absorption unit. This detailed energy measurement provided data used to determine how much power Rotor 2 could develop. The resulting equation for the developed power in watts is $P=1.72 \times B \times \omega \times i$, where $B$ is the field strength in Tesla at the rotor coil's midplane (1.8Z Tesla), $\omega$ is the angular velocity in rad/s, and $i$ is the rotor current in amps. The second case was a measurement of $15.3 \mathrm{~kW}$ power delivered to the load by the rotor with developed power calculated to be $18 \mathrm{~kW}$ at the maximum rotor current. Current was limited to $33 \mathrm{~A}$ because one inverter was inoperative. The hypothetical case is an estimate of the potential $44.2 \mathrm{~kW}$ of developed power at design conditions for delivery of $41.4 \mathrm{~kW}$ to the load at $94 \%$ efficiency. These calculations are based on results from this motor characterization with the squirrel cage bolts insulated to eliminate $1.3 \mathrm{~kW}$ of loss. 


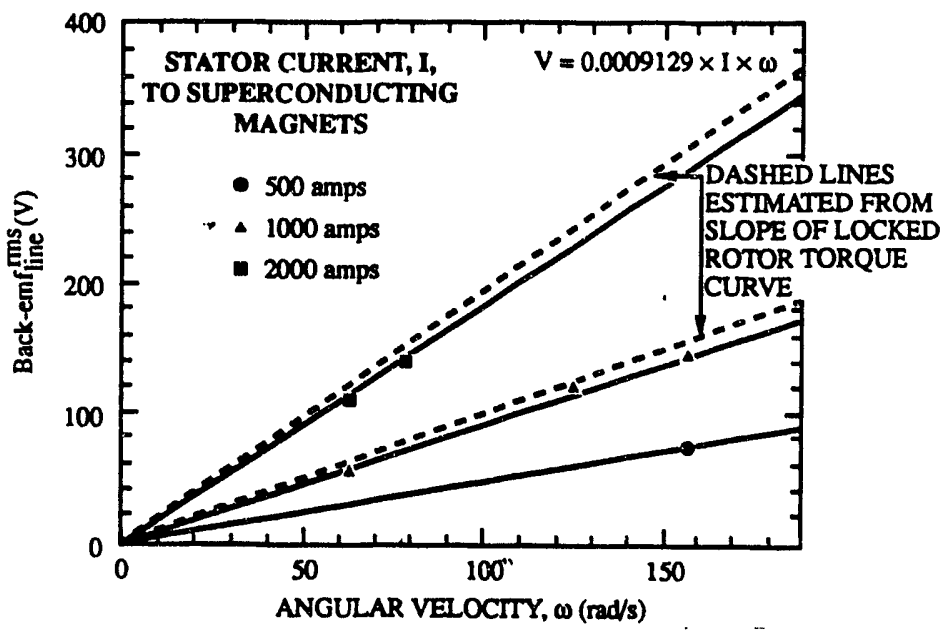

Fig. 5. Back emf generated by Rotor 2 .

\section{CONCLUSIONS}

1. A test bed axial-gap motor with a stator whose electromagnets are lowtemperature superconductors has provided a baseline for comparison with subsequent operation with a stator whose electromagnets are high-temperature superconductors.

2. The rotor developed $18 \mathrm{~kW}(24 \mathrm{hp})$ at a rotor current of $33 \mathrm{~A}$ and a stator current of $2000 \mathrm{~A}$ and delivered $15.3 \mathrm{~kW}(20.5 \mathrm{hp})$ to a load.

3. Measurements of parasitic mechanical and EM drags have provided information suggesting design changes for improving efficiency.

4. A detailed efficiency measurement and successful operation of the stator at $2500 \mathrm{~A}$ indicated that the test bed motor is capable of developing $44.2 \mathrm{~kW}(59.2 \mathrm{hp})$ at a design current of $60 \mathrm{~A}$ and a stator current of $2500 \mathrm{~A}$. Power delivery to a load is expected to be $41.4 \mathrm{~kW}$ (55 hp).

\section{REFERENCES}

1. S.W. Schwenterly, J.N. Luton, J.W. Lue, W.J. Kenney, and M.S. Lubell, and Testing of a Four-pole Superconducting Motor Stator," Advances in Cyyogenic Engineering, Vol. 37A, p. 473-479 (1991).

2. R.A. Hawsey, W.K Kahl, S.W. Schwenterly, J.M. Bailey, C.W. Sohns, J.N. Luton, B.W. McConnell, V.W. Campbell, "Analysis and Performance of an Axial-Gap Superconducting Motor," IEEE Trans on Magnetics, Vol. 27, No. 2, (1991).

3. A. Schilling et al., "HgBaCaCuO with Transition Temp at $133 \mathrm{~K}$." Nature, Vol. 363, (May 6, 1993).

4. C. Gillespic ed., "One Small Step: An SC Motor is Tested Successfully," Superconducting Indusiry, (Spring 1993).

5. P.K Tompkins, "Reliance Electric Announces Progress on Superconducting Motors," News Release, No. 93-8, (April 26, 1993).

6. S.J. Dale, S.M. Wolf, and T.R. Schneider, "Energy Applications of High-Temperature Superconductivity-Extended Summary Repor," Electric Power Research Institute, ER-6682, Vol. I, (February 1990).

7. J.M. Bailey et al., "A Self-Starting, Axial-Gap Permanent Magnet Motor and Adjustable-Speed Drive," Proc. IEEE Southeastem Conference, 718-522 (1988)

8. R.A. Hawsey et al., "High Power Density Generator Concepts for Aerospace Electric Power," Proc. of the 24th Intersociery Energy Conversion Engineering Conference, Washington D.C., pp. 1109. 1114 (1989). 
Presentation Viewgraphs:

1. Title Slide

2. Collaborators in Characterization of the Test Bed Motor

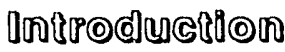

3. Presentation Outline

4. Project Objectives

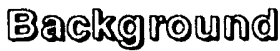

5. The SMRF Mascot Pays a Visit (photo)

6. Axial Gap Superconducting Motor (cartoon)

7. SMRF Motor Characterization Team - 1992 (photo)

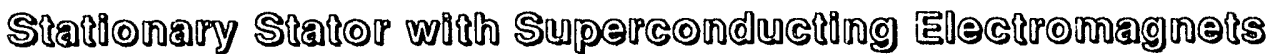

8. SMRF Superconducting Stator and Designer (photo)

9. Cutaway of SMRF Cryostat (X-10 Graphic Arts)

10. SMRF Niobium-Titanium Superconducting Electromagnets (photo)

11. SMRF Magnet Case (photo)

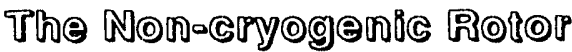

12. SMRF Rotor 1 - 1990 (photo)

13. Rotor 2 Coil Winding (photo)

14. Rotor 2 after Potting (personal photo)

(48 phr Genimide 151 hardener in DER 324 epoxy)

15. SMRF Rotor 2 - 1992 (photo)

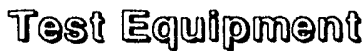

16. Instrumentation for Measuring Total Electrical Power to the Superconducting Motor

17. SMRF Auxilliary Drive Motor and Dynamometer (photo)

Papasild L๑S Leses

18. Eddy Current Loss in a Strand of Wire

19. Two Types of Parasitic Circulation Currents

20. Parasitic Torque in Rotor 2

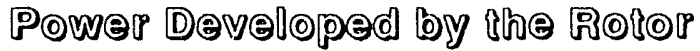

21. Locked Rotor Torque

22. Estimate of Back-emf from Locked Rotor Torque

23. Rotor 2 Back emf

24. Current and Voltage Waveforms

25. Power Developed by Rotor 2

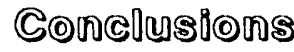

26. Power Developed and Delivered By SMRF Test Bed Motor

27. Conclusions 


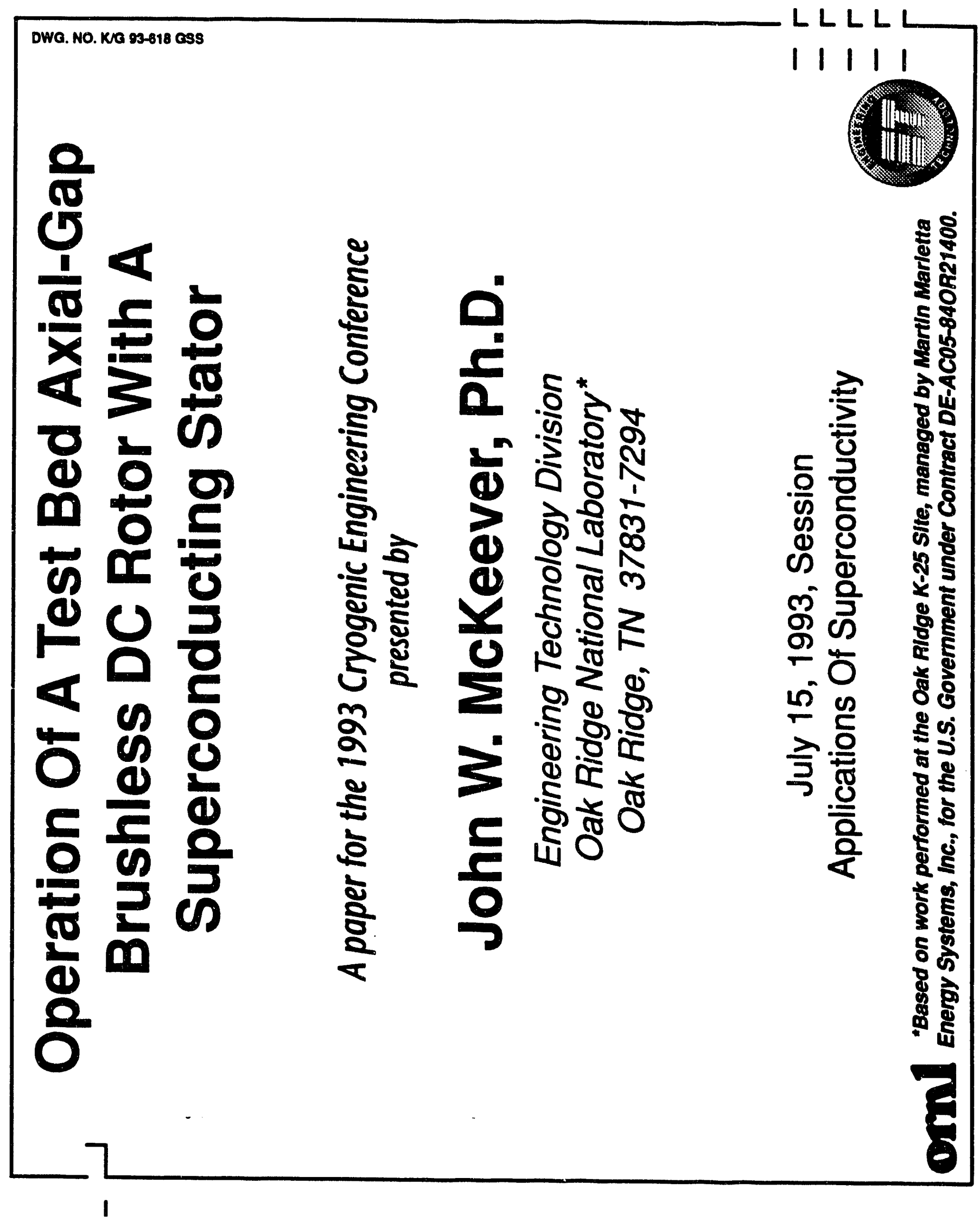




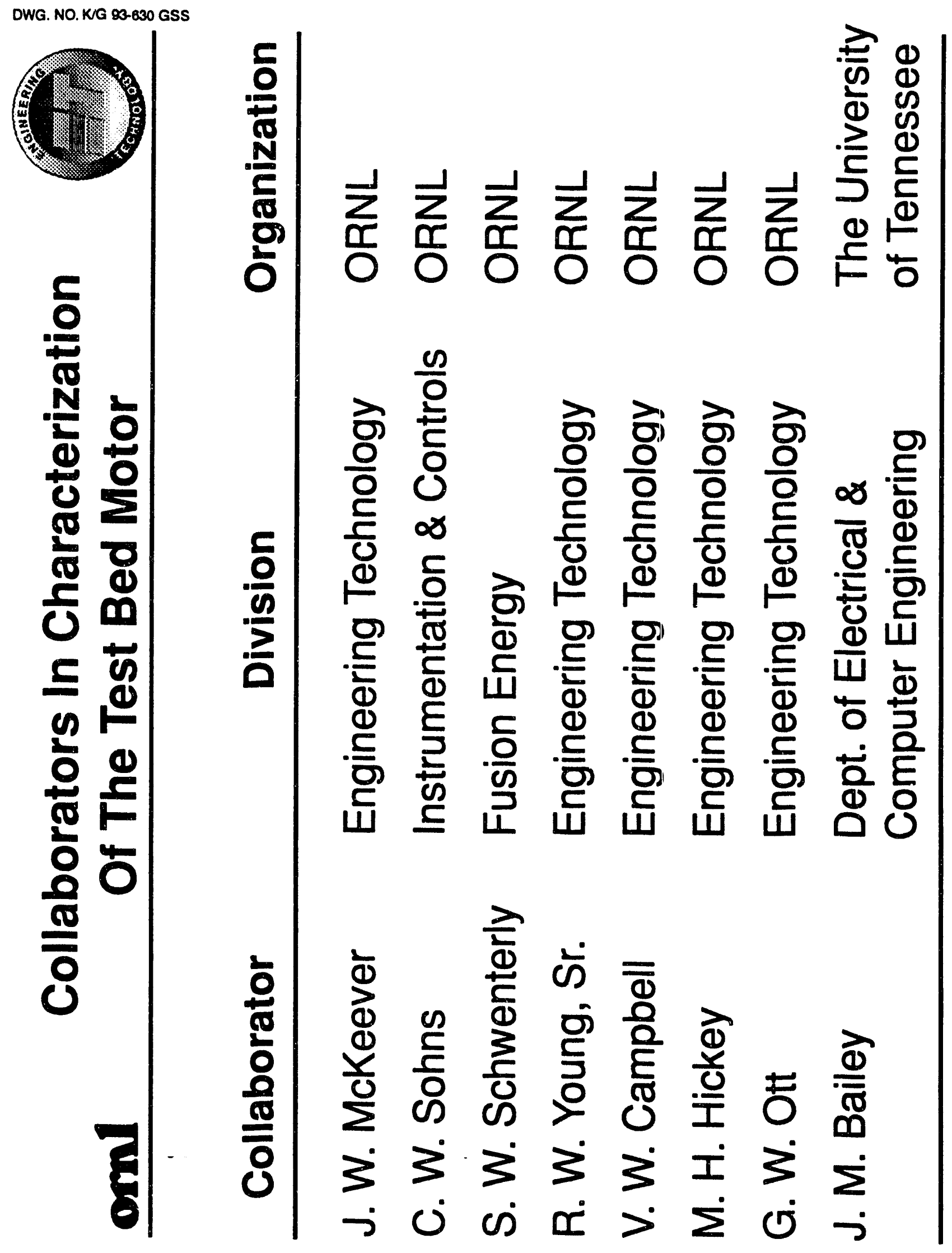


DWG. NO. KG 93-631 GSS

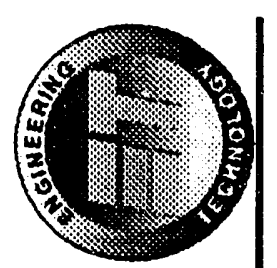

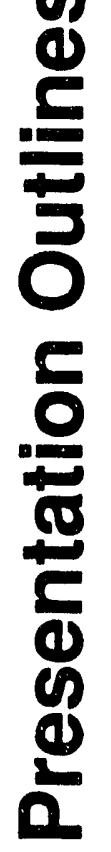

$\stackrel{\infty}{E}$

이

ํㅡㅇ

을

$\begin{array}{ll}\frac{2}{3} & \frac{1}{0} \\ \text { 을 } & \frac{1}{2}\end{array}$

$\frac{5}{0}$

\pm 당

$\sum_{1} \frac{U}{5}$

E

융 Ð

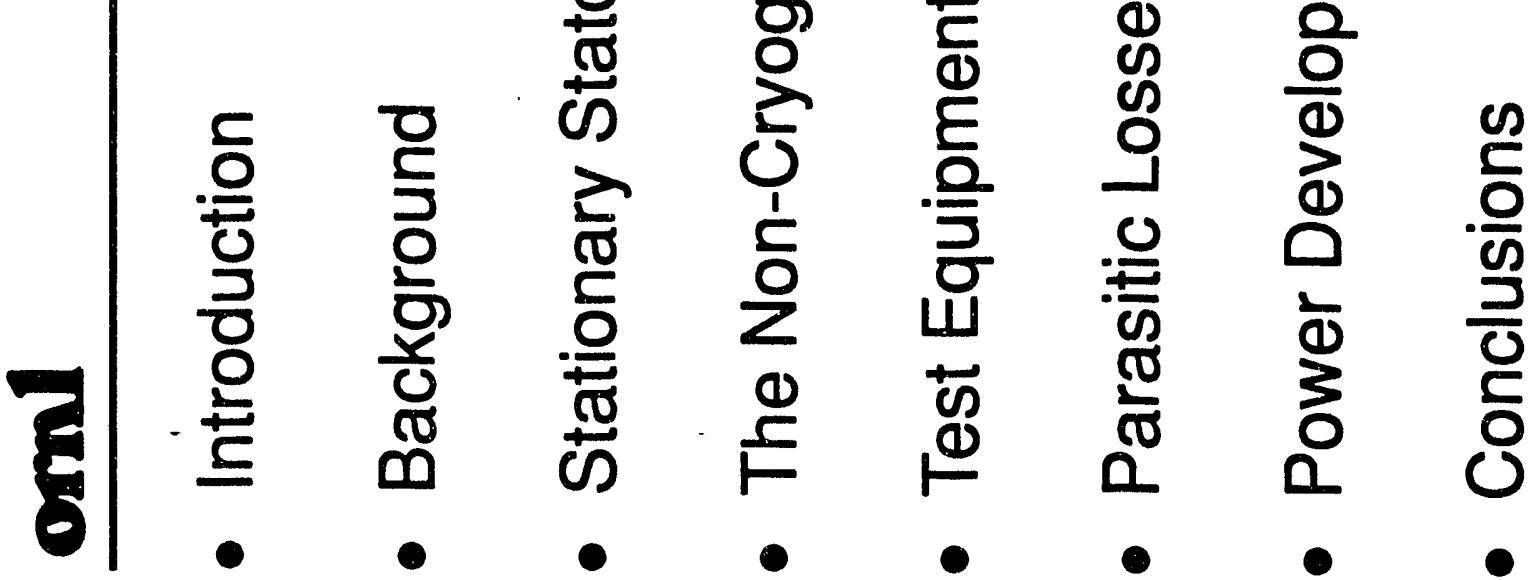




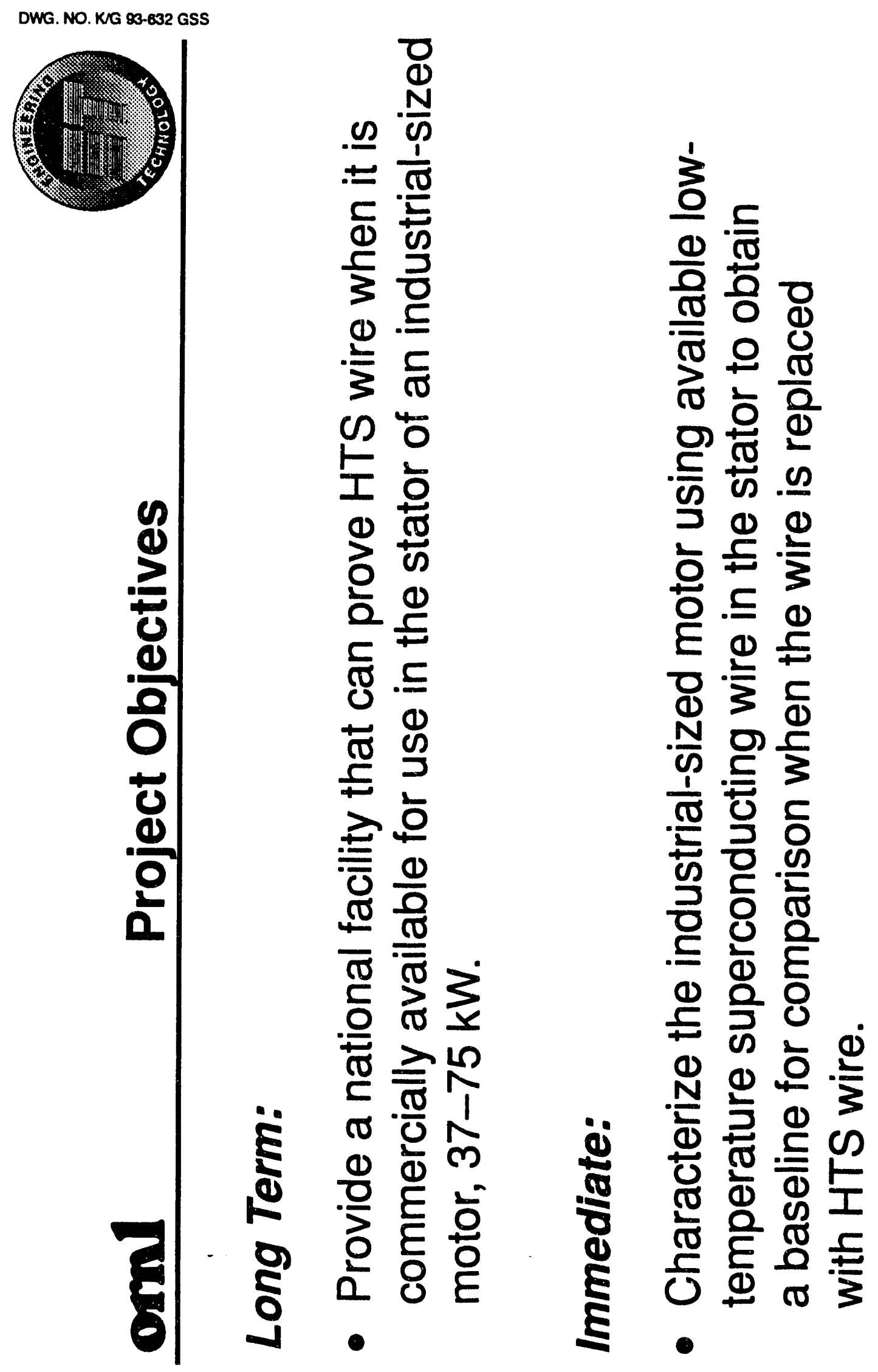


ORNL-DWG 93M-10546

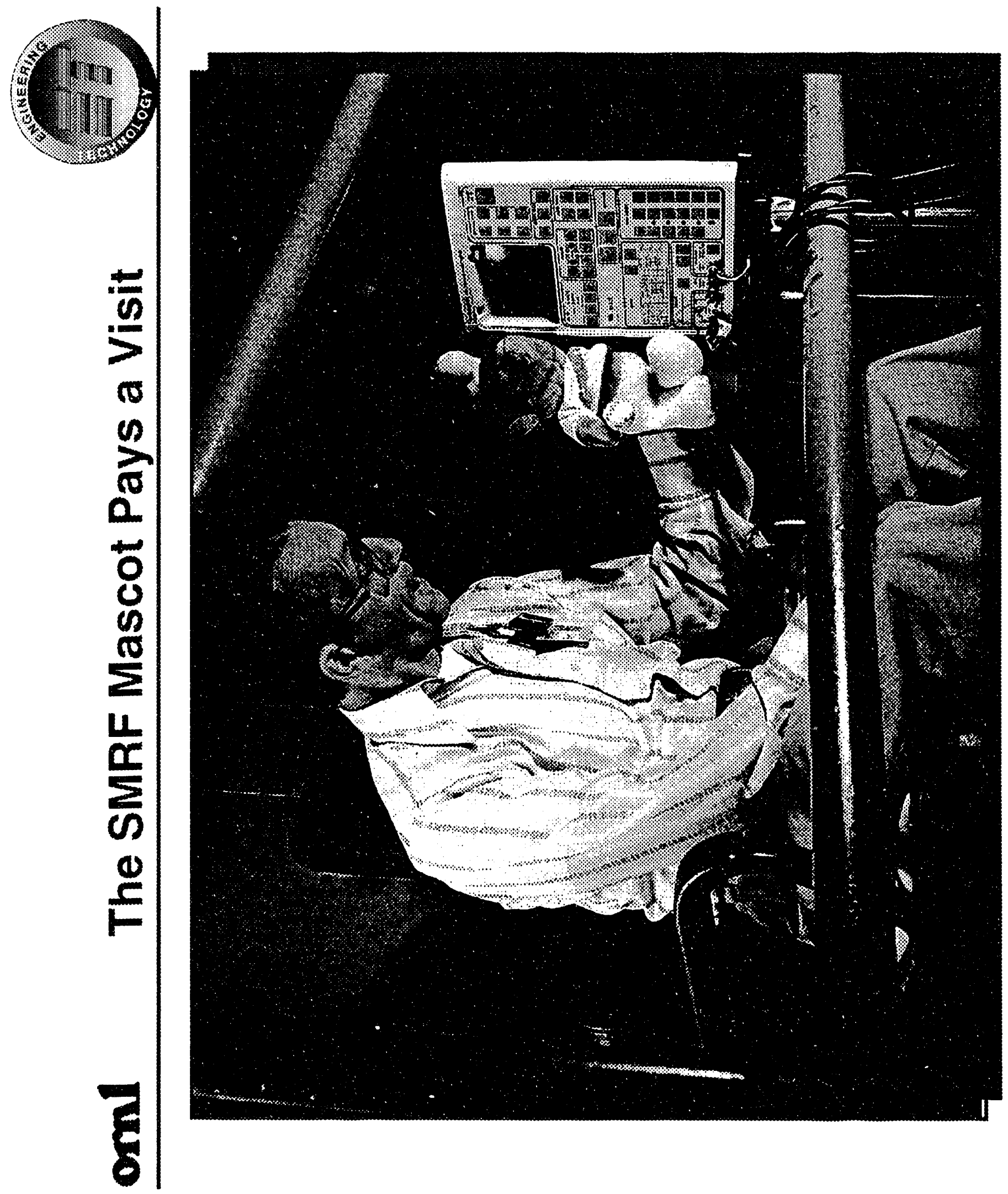


DWG. NO. KG 93-614 GSS

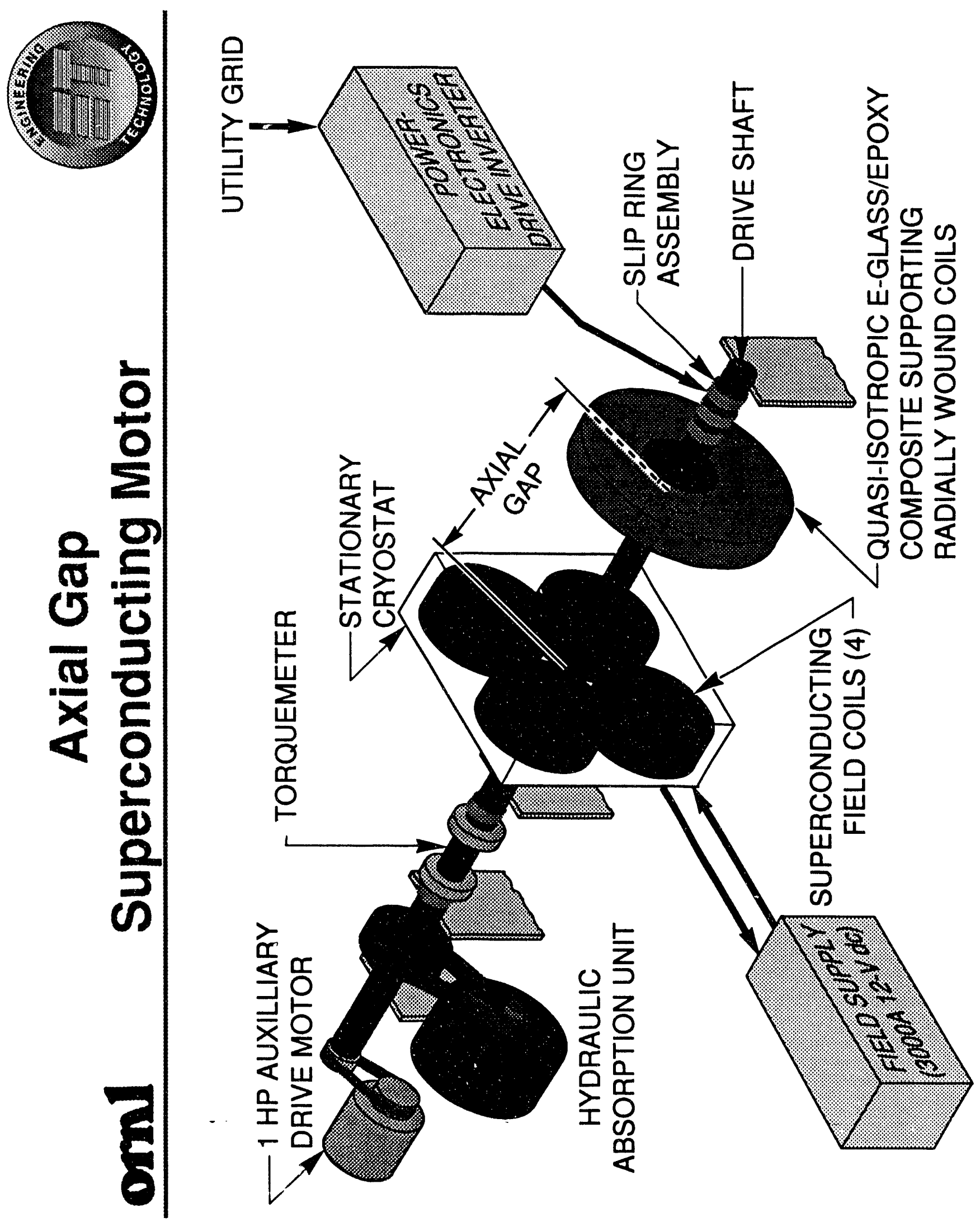




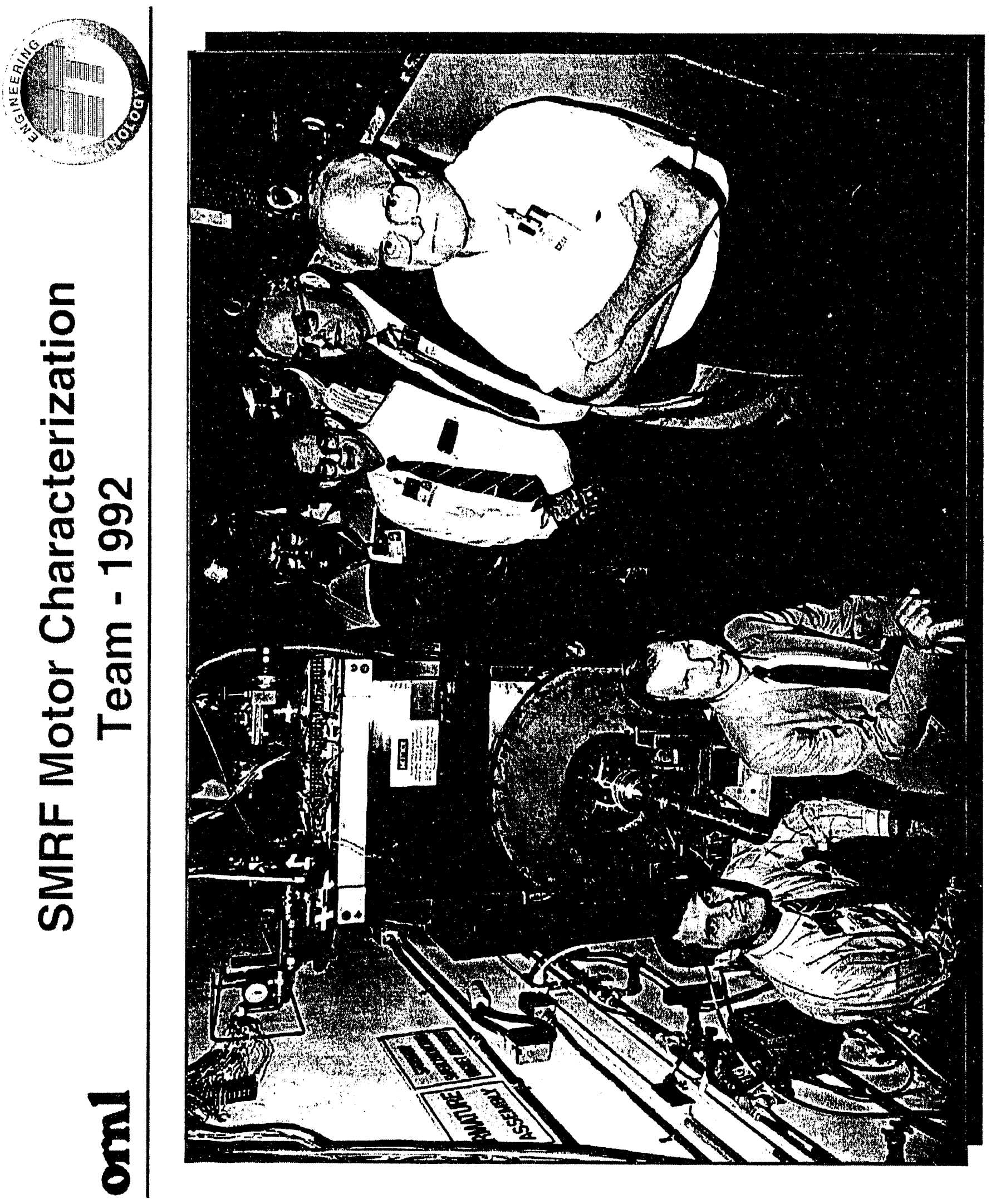


ORNL-DWG 93M-10539

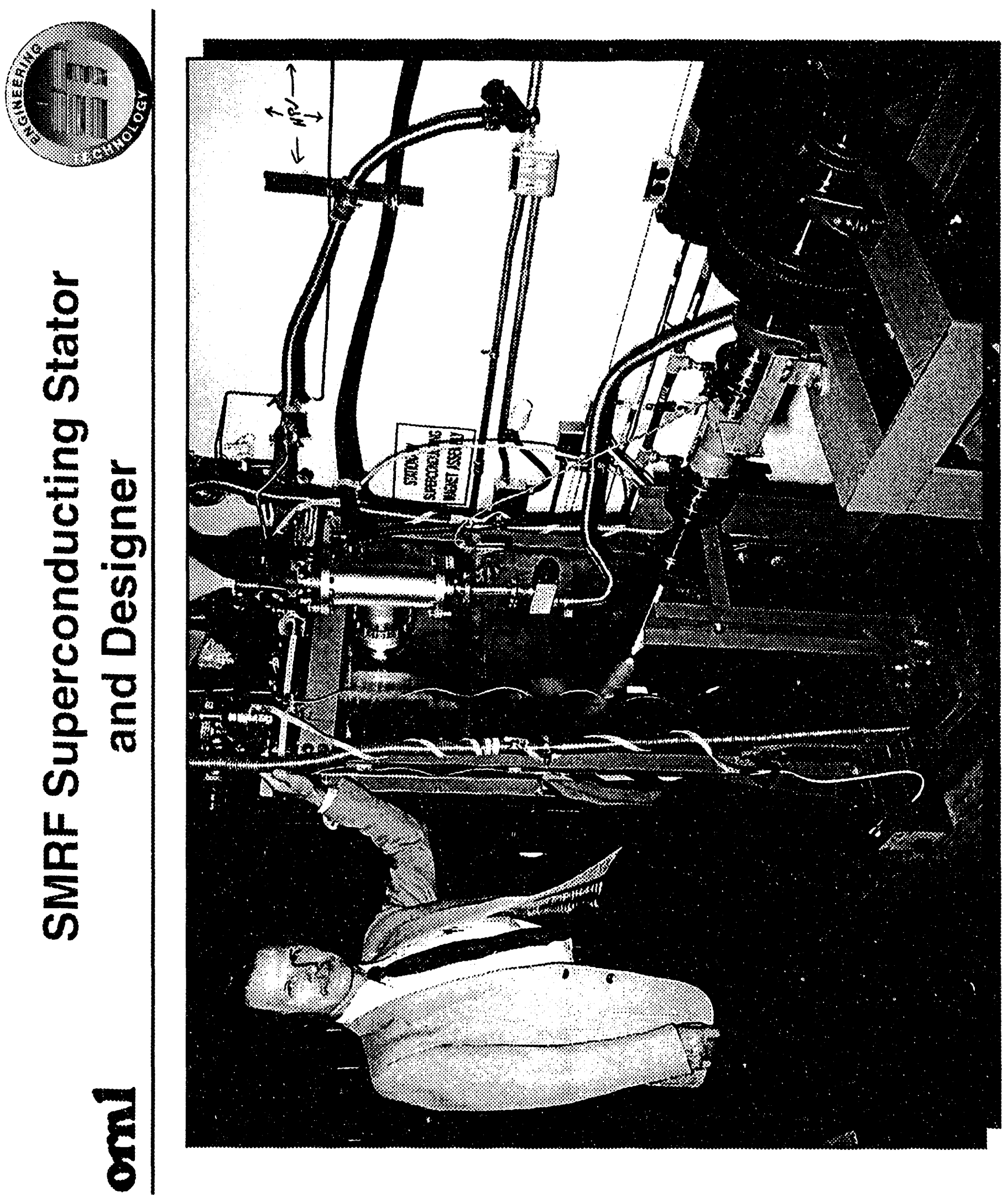


ORNL-DWG 93M-10511

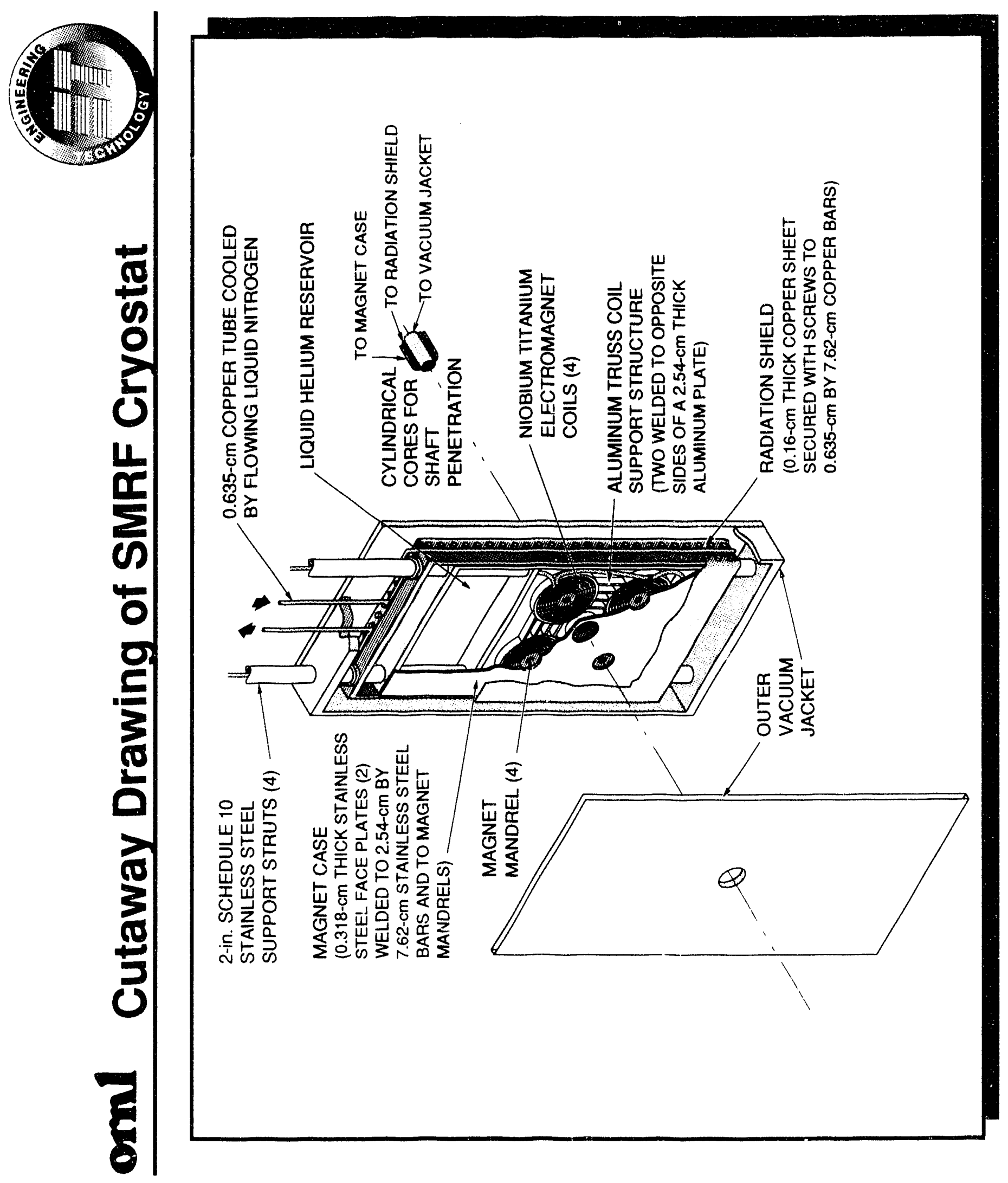




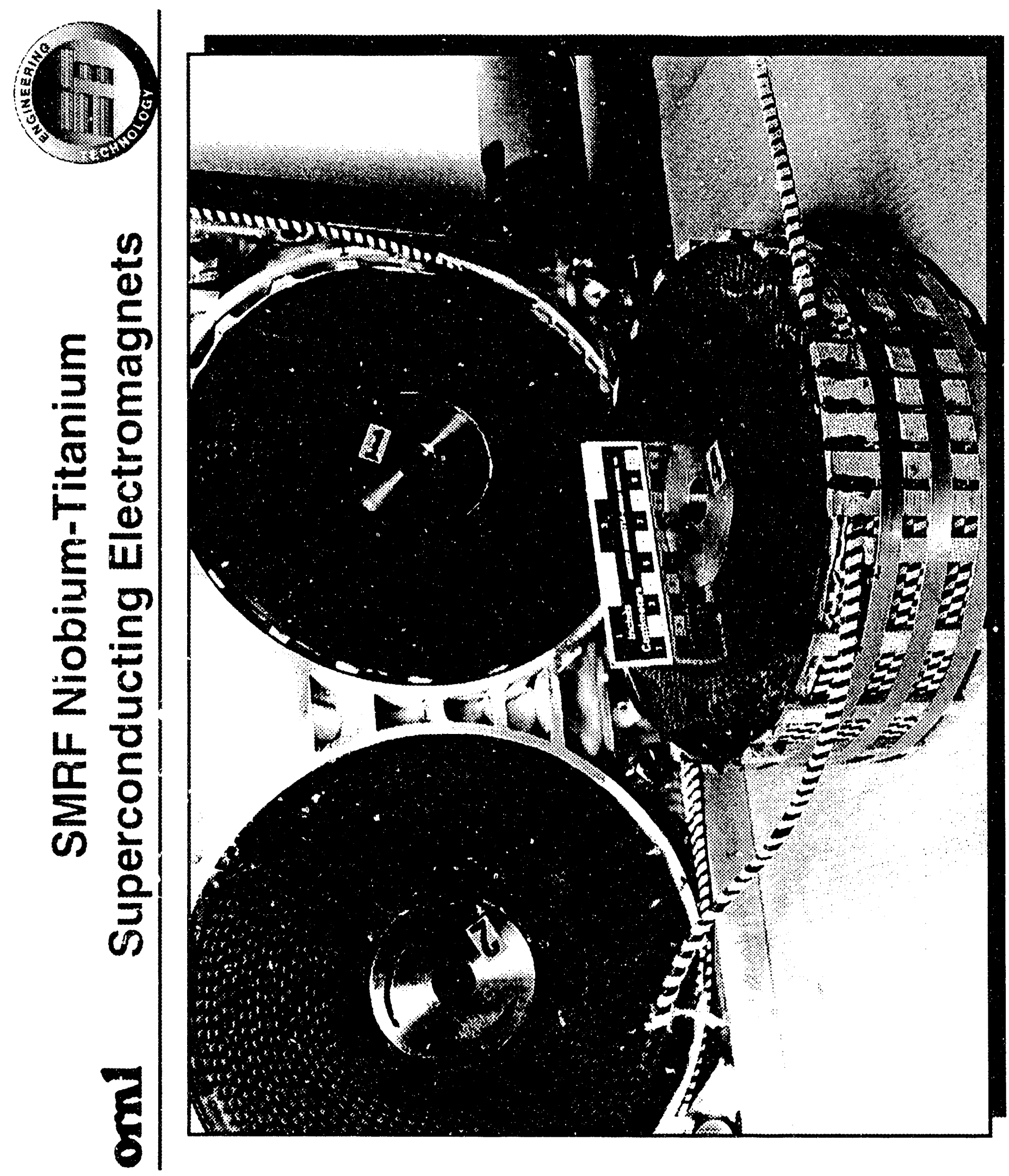


ORNL-DWG 93M-10541

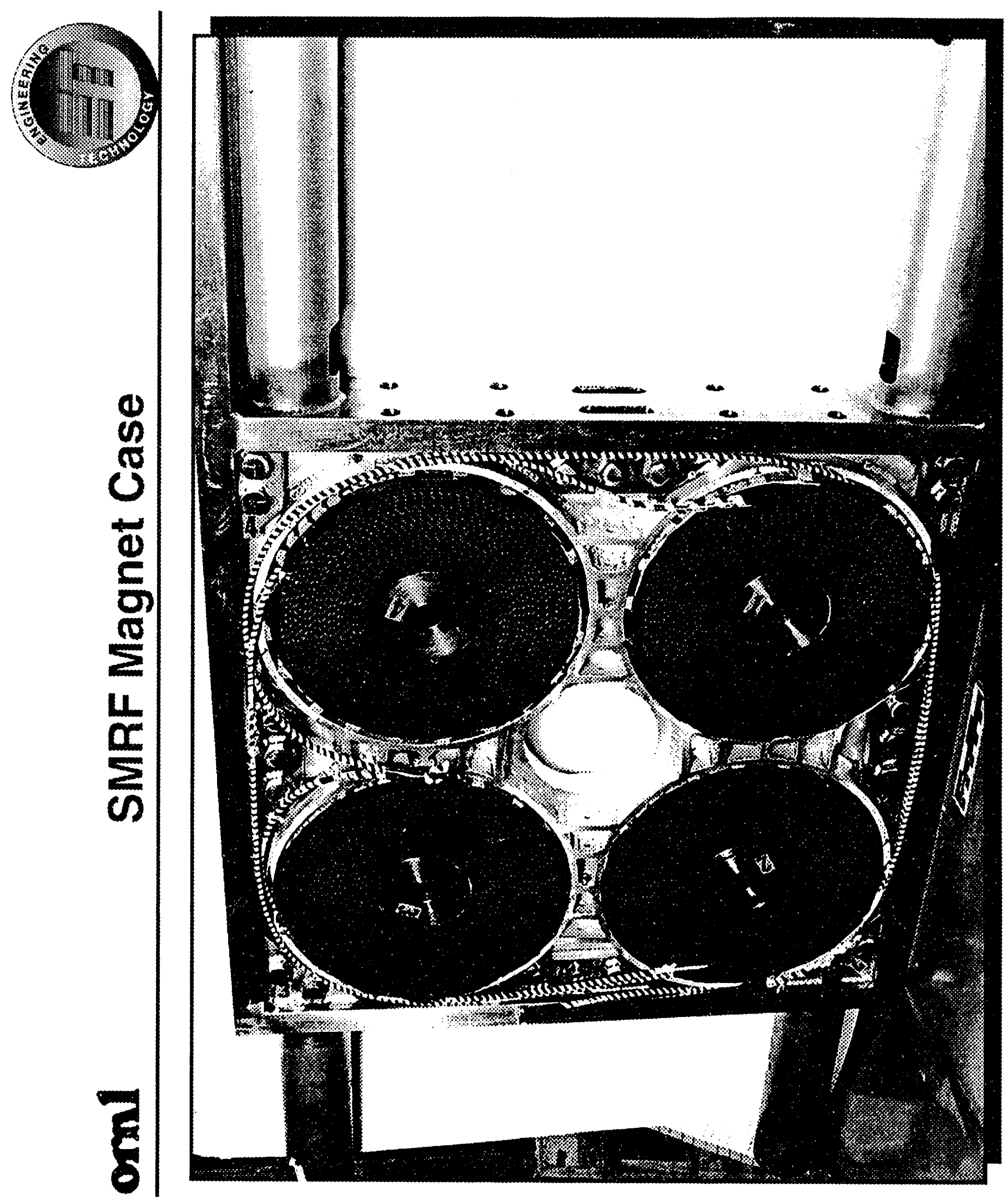


OANL-DWG 93M-10535

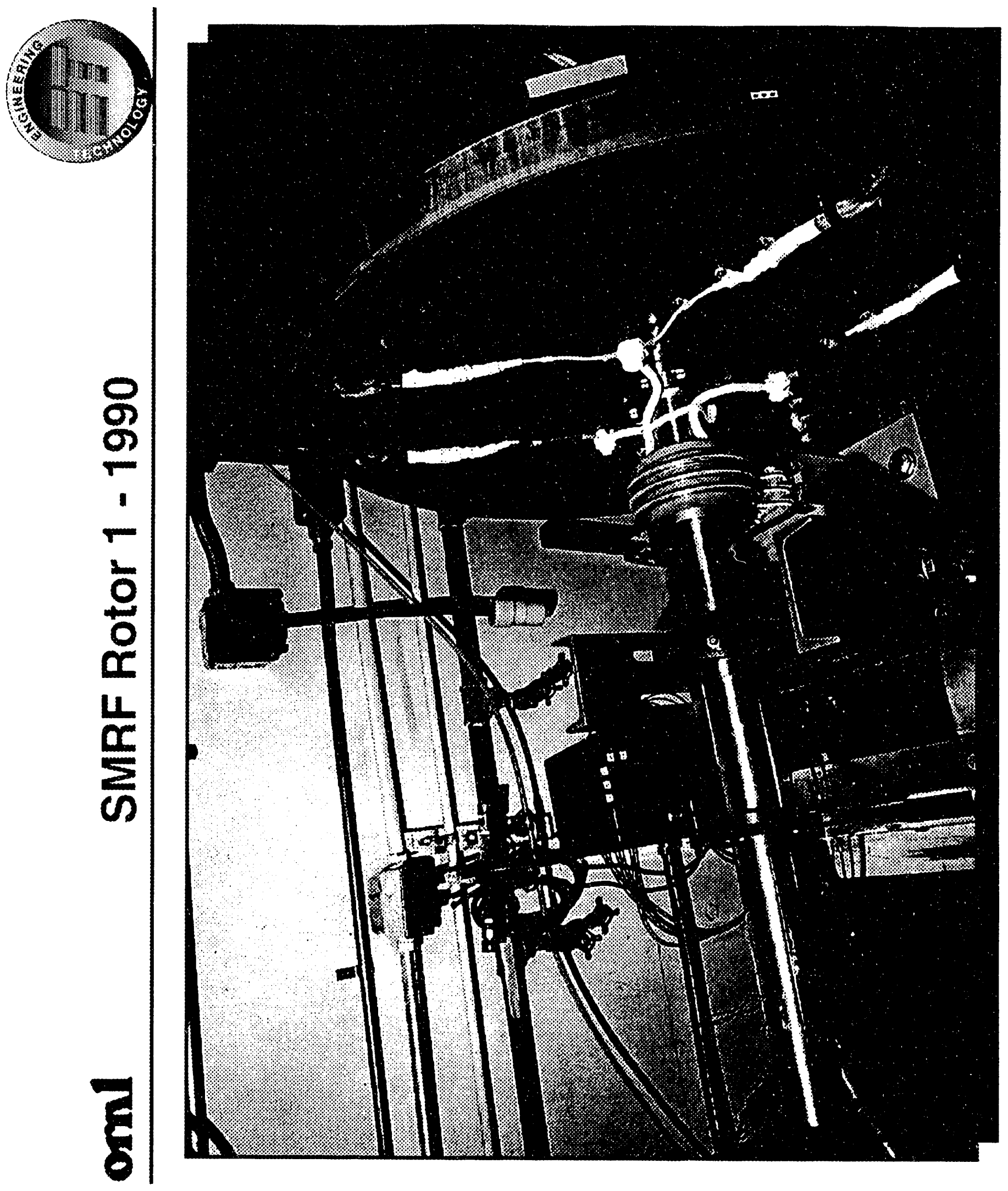


ORNL-DWG 93M-10537

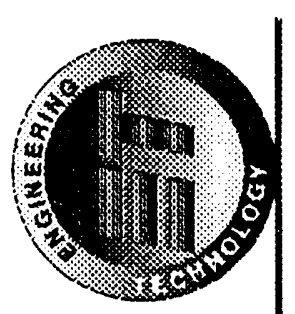

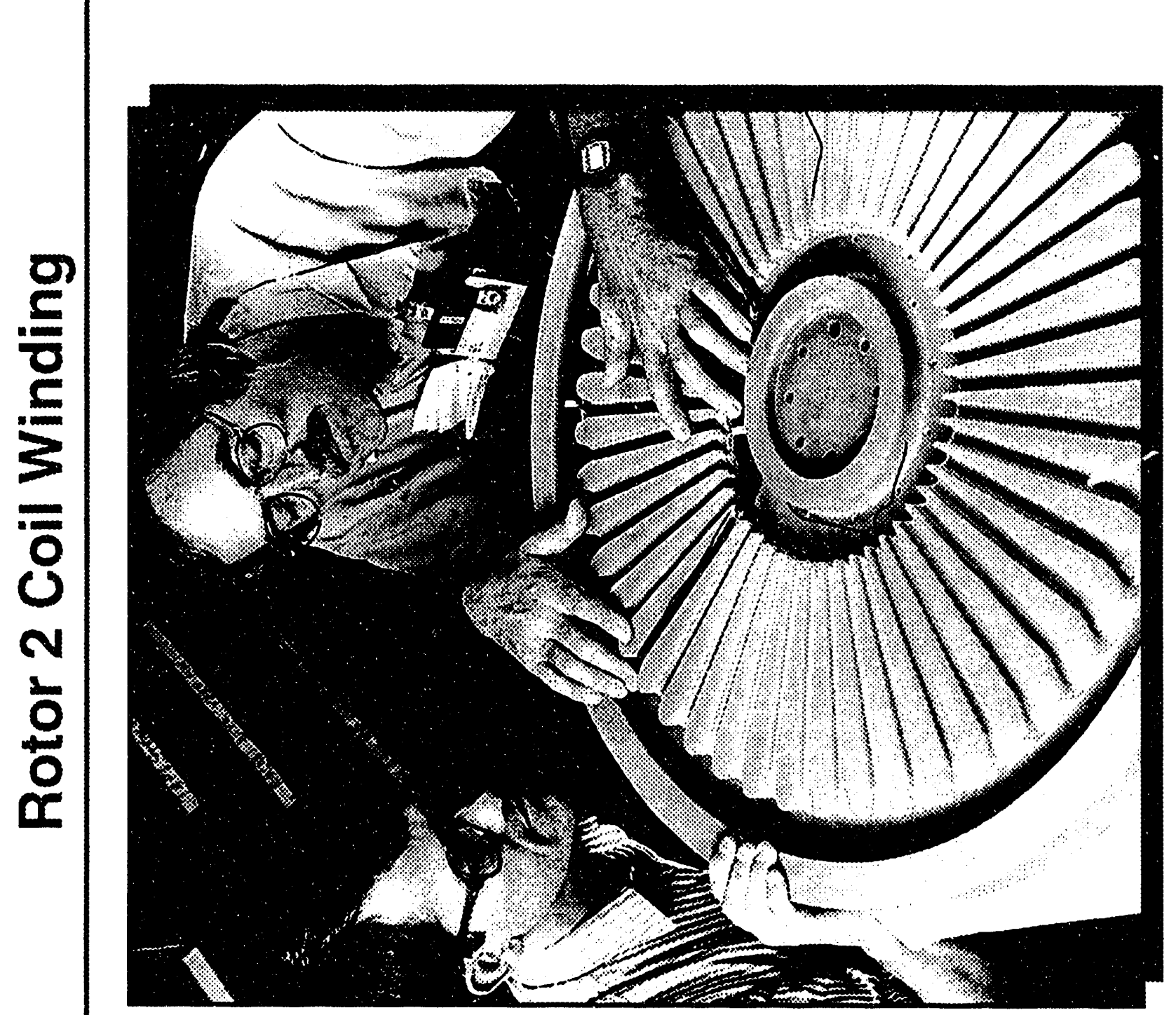




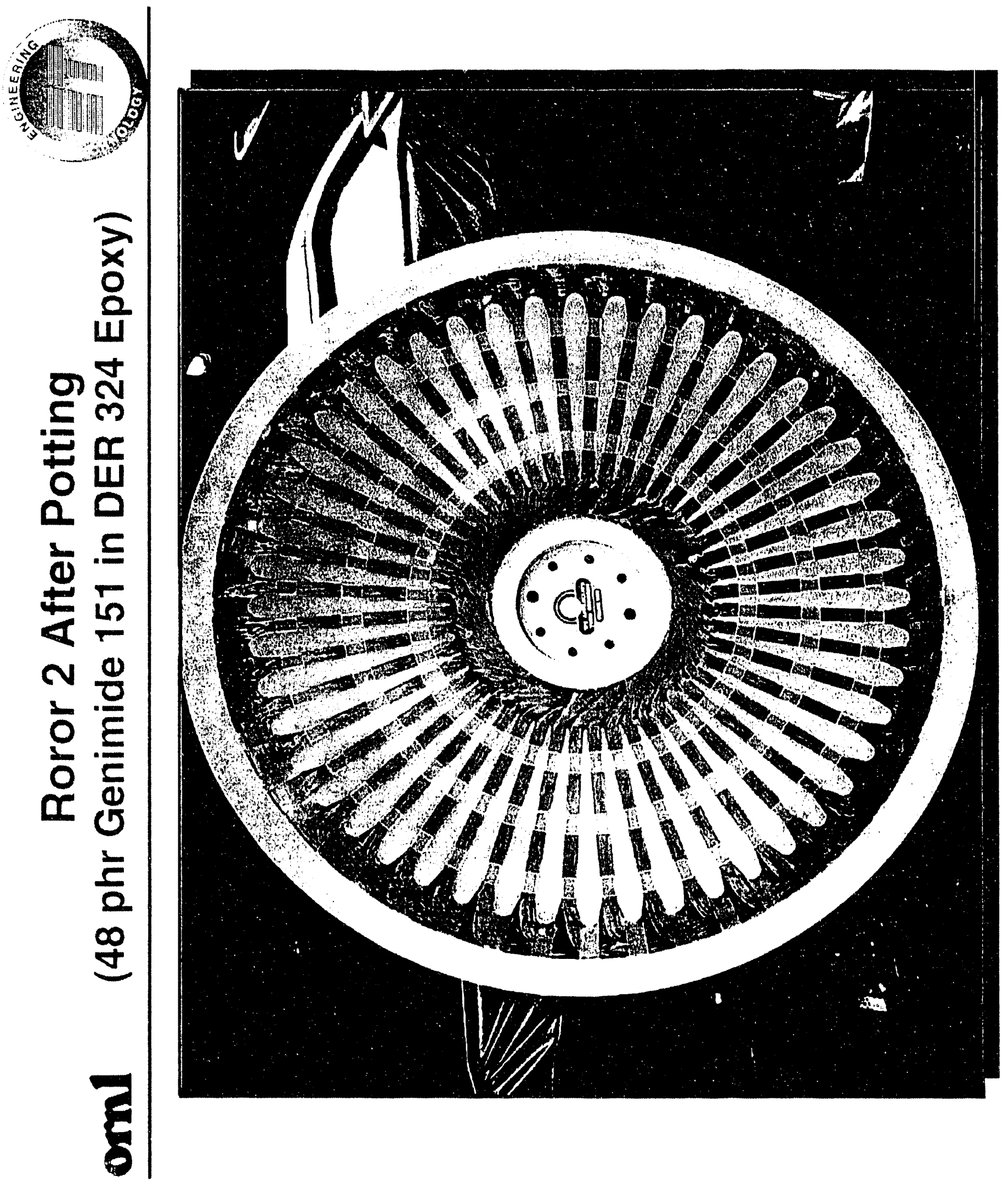


ORNL-DWG 93M-10536
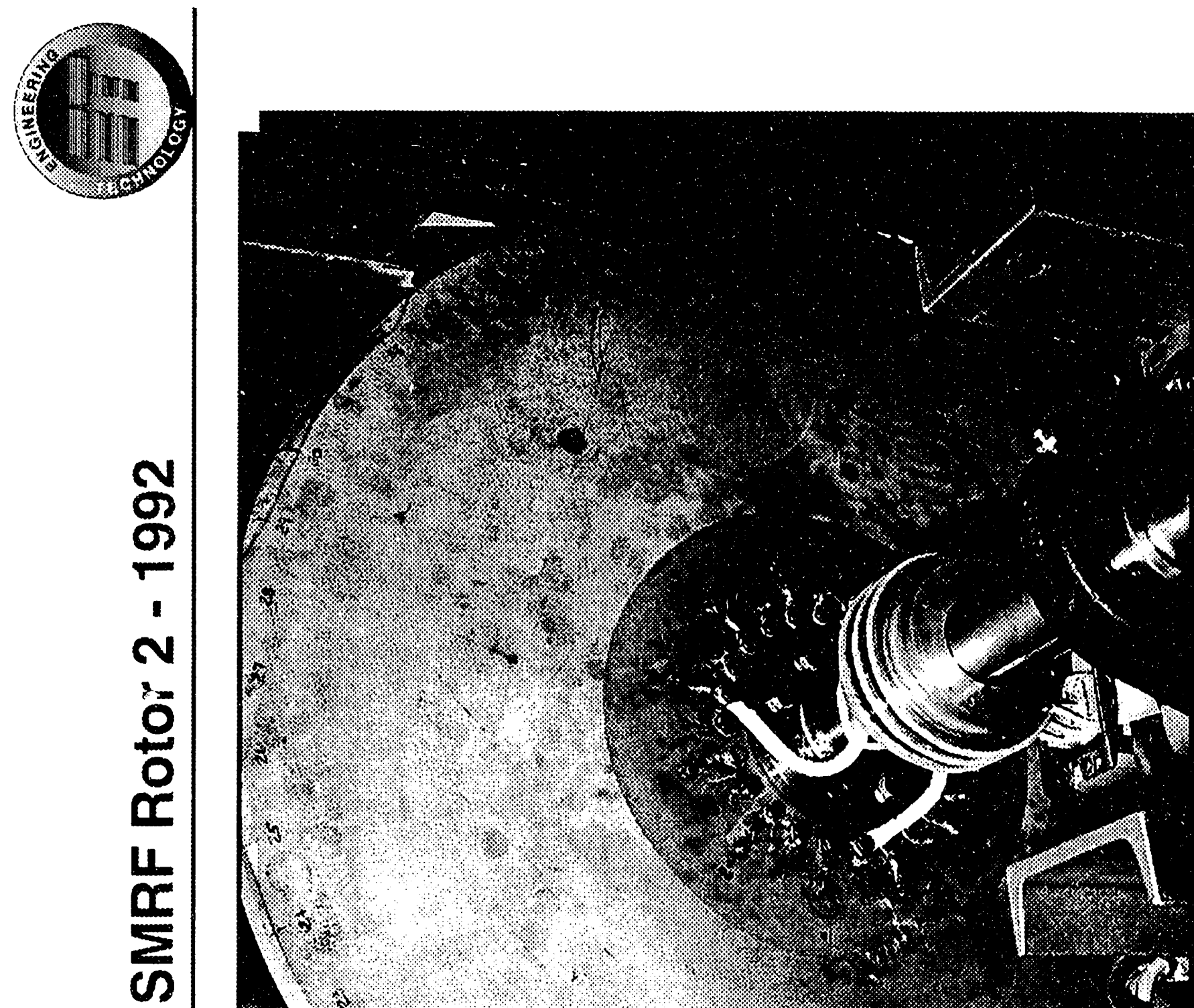

2.
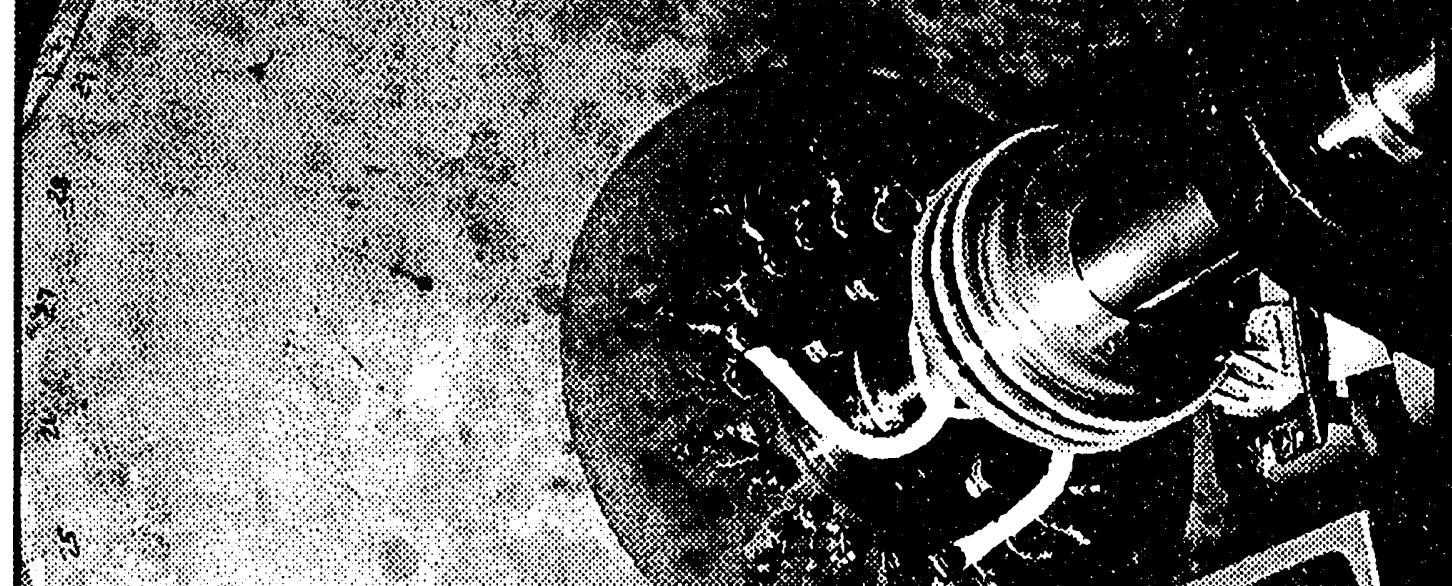

.

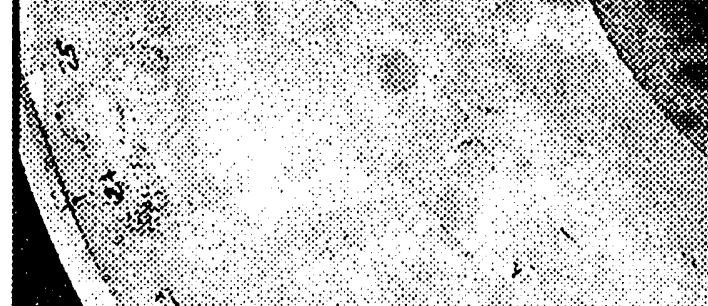

,

\%

.

,

and

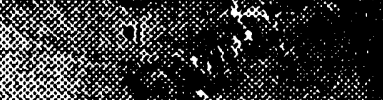

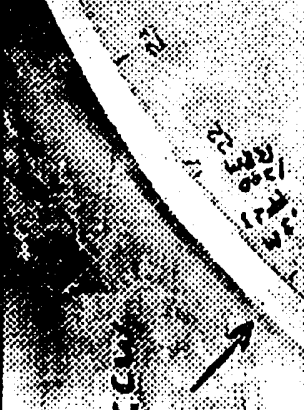

1. 1.1 .2 .8 .8 .

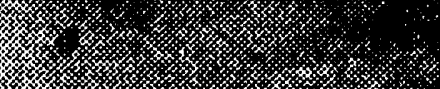

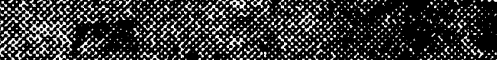

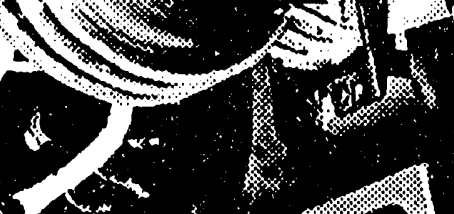

, r
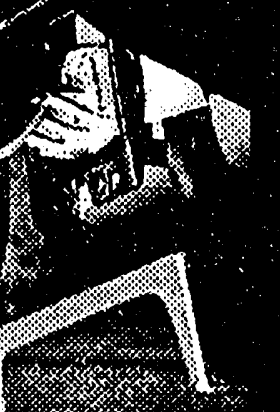

$8 \%$

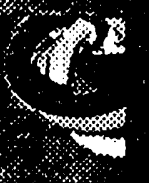

.

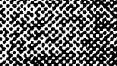

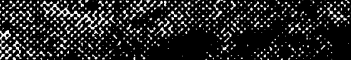

$\%$ \% 
DWG. NO. KG 93-606 GSS

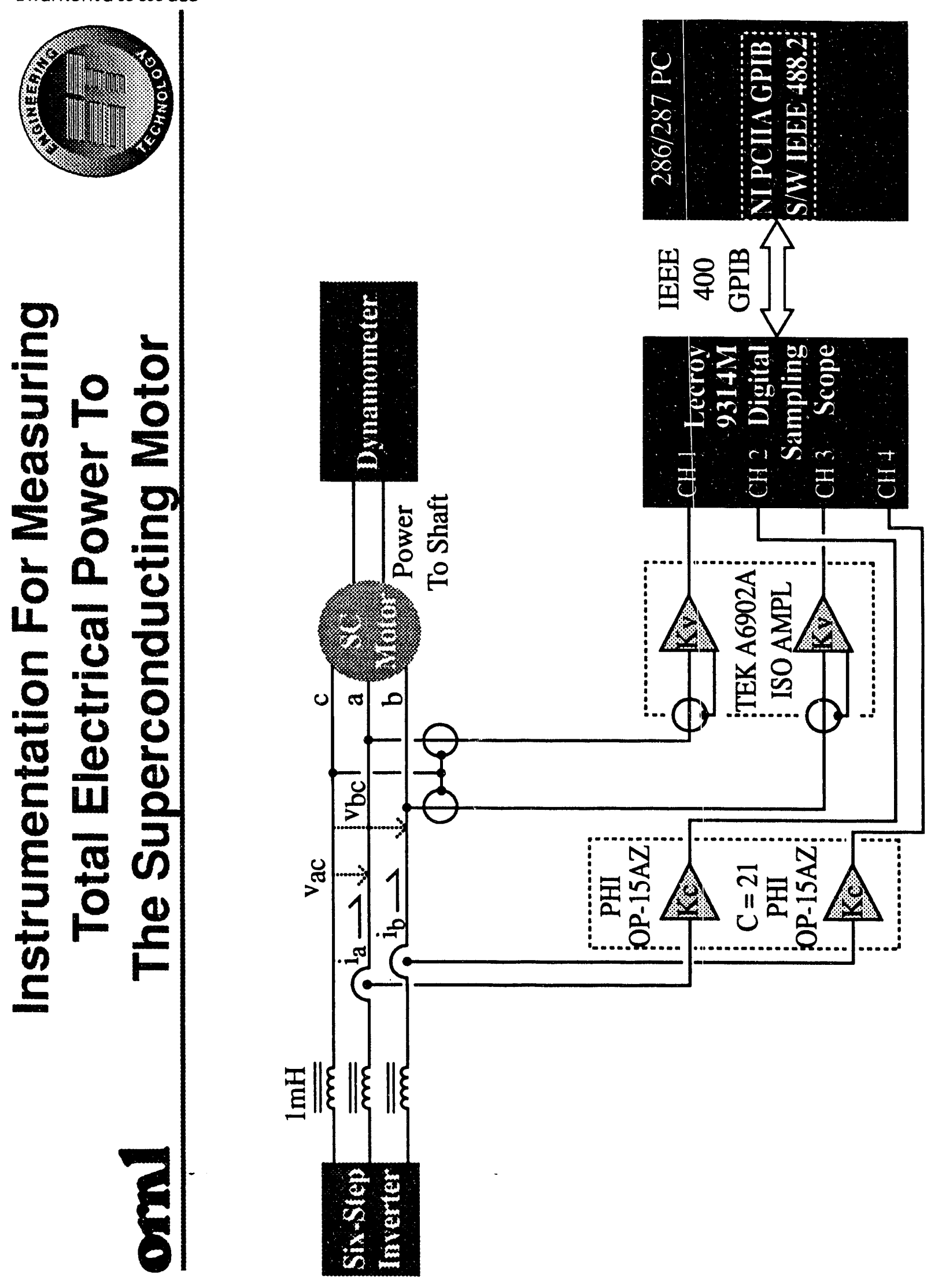




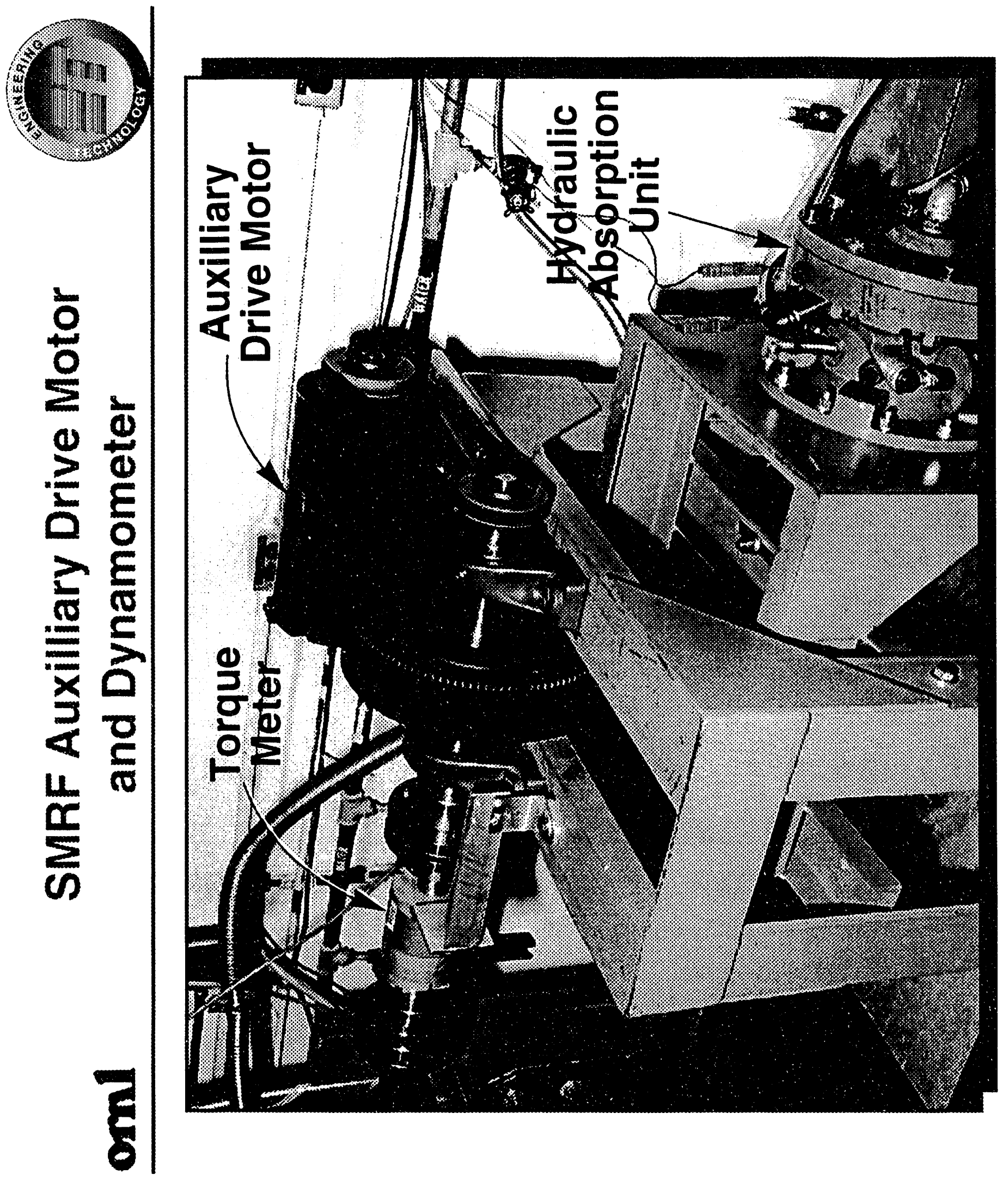




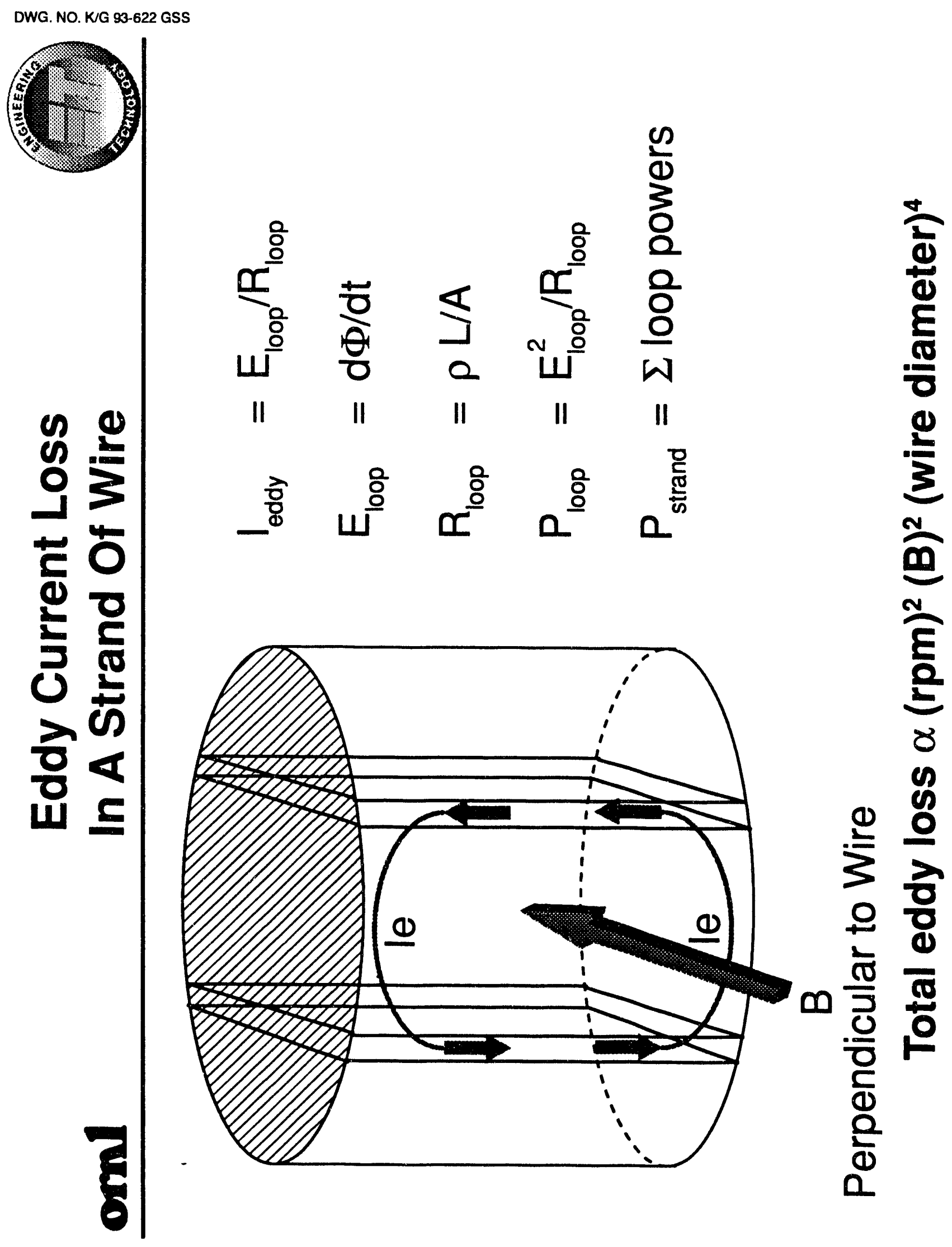




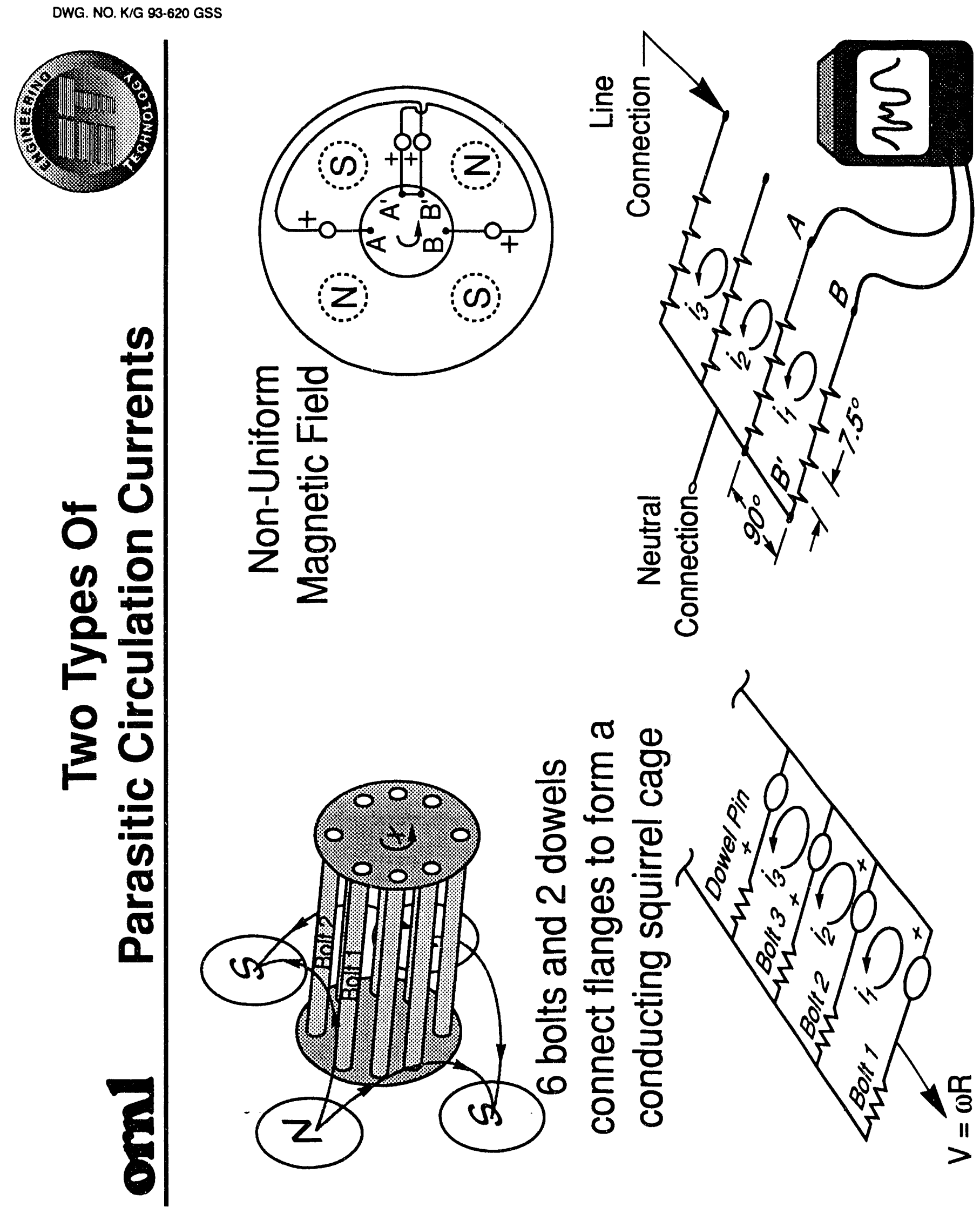


DWG. NO. KG 93-602 GSS

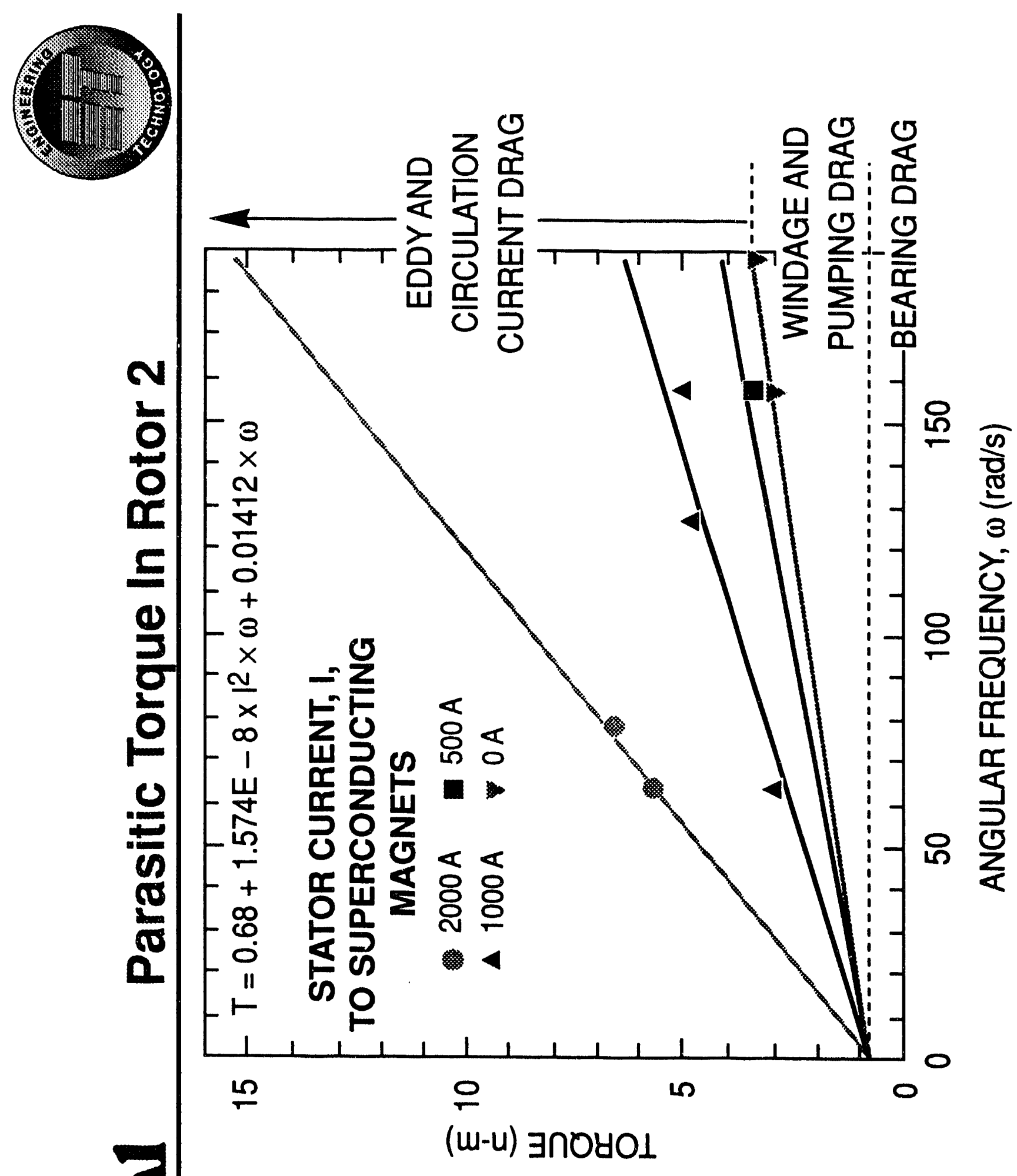


DWG. NO. KJG 93-605 GSS

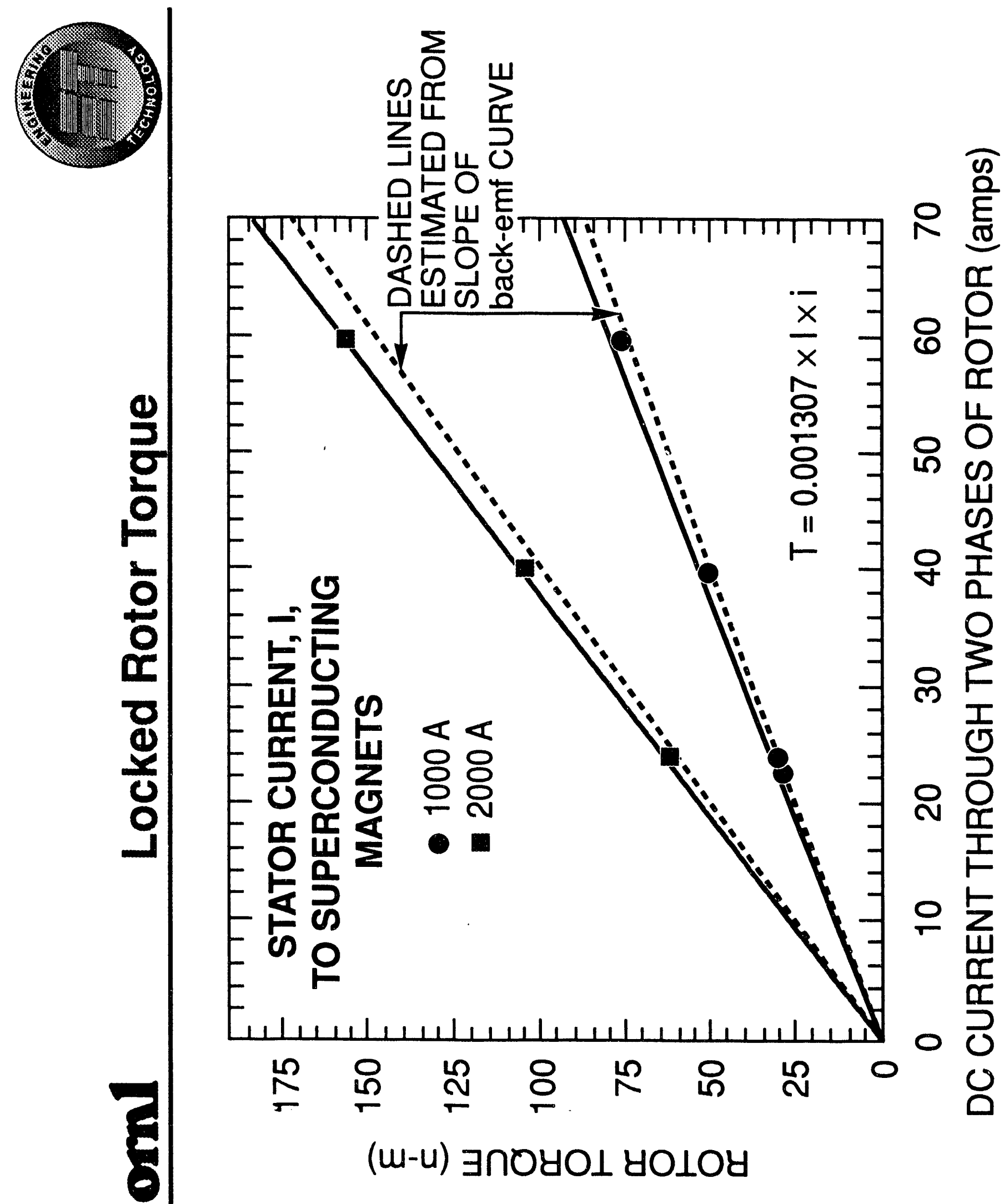


DWG. NO. K/G 93-623 GSS

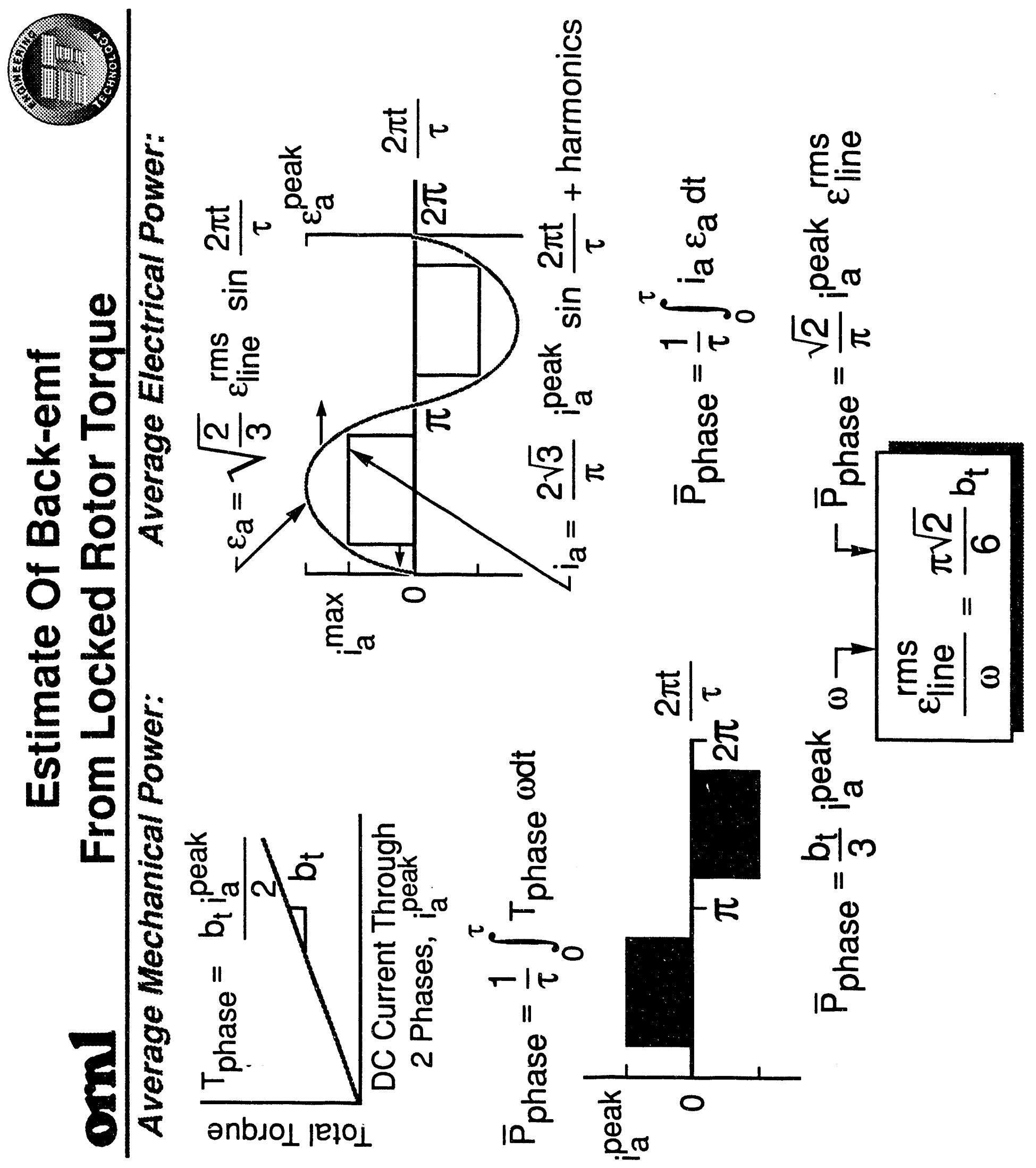


DWG. NO. K/G 93-604 GSS

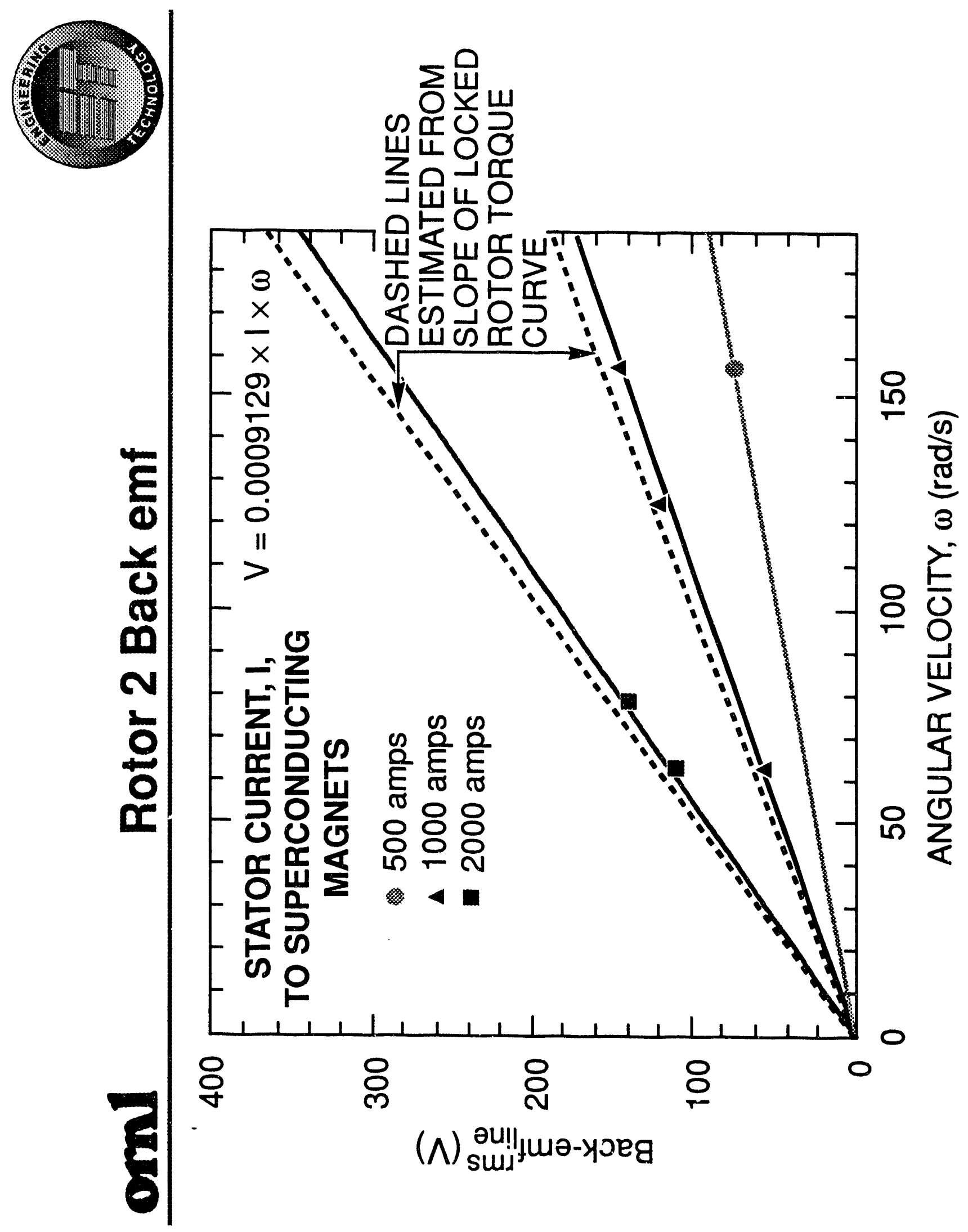


D'NG. NO. K/G 93-619 GSS

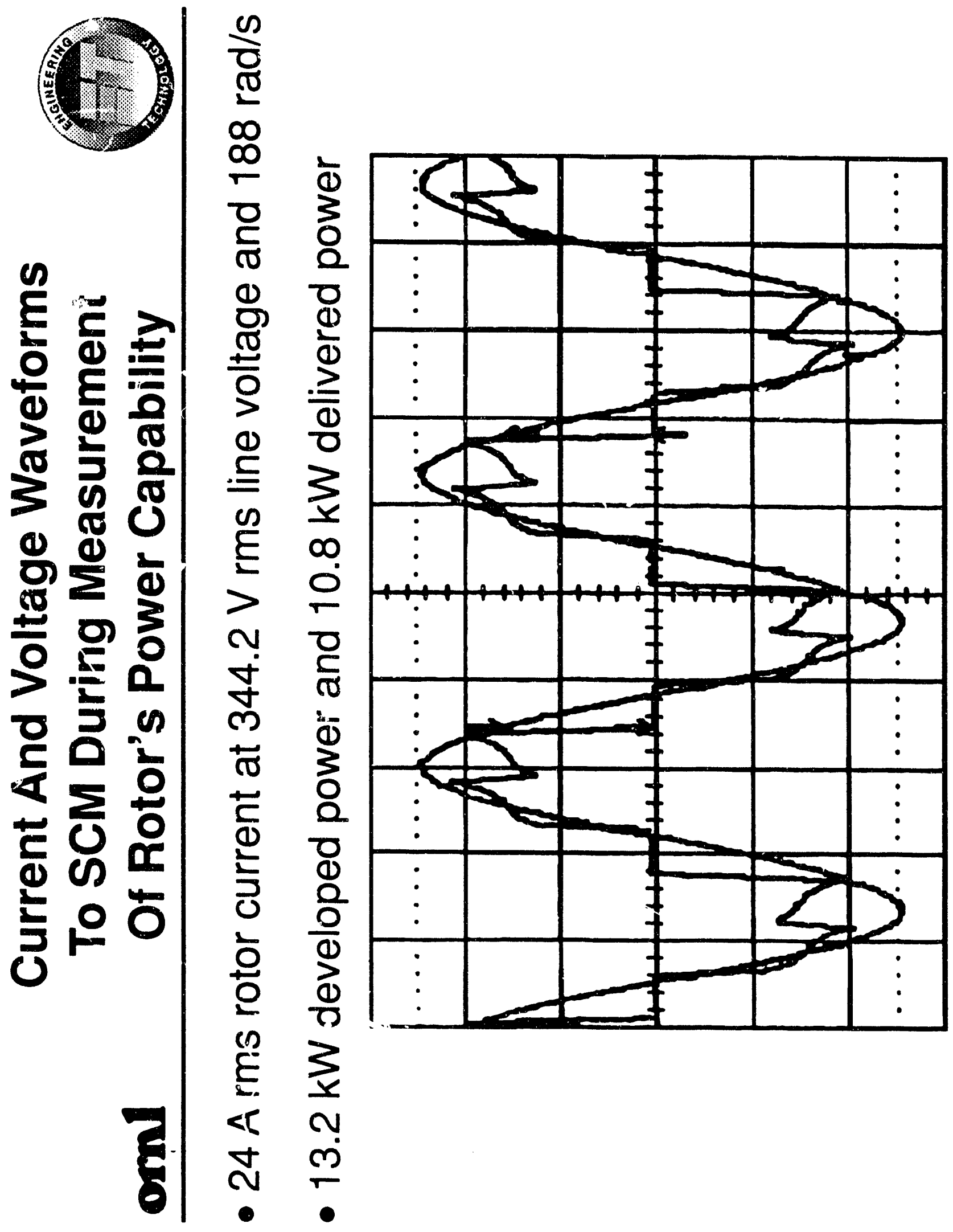




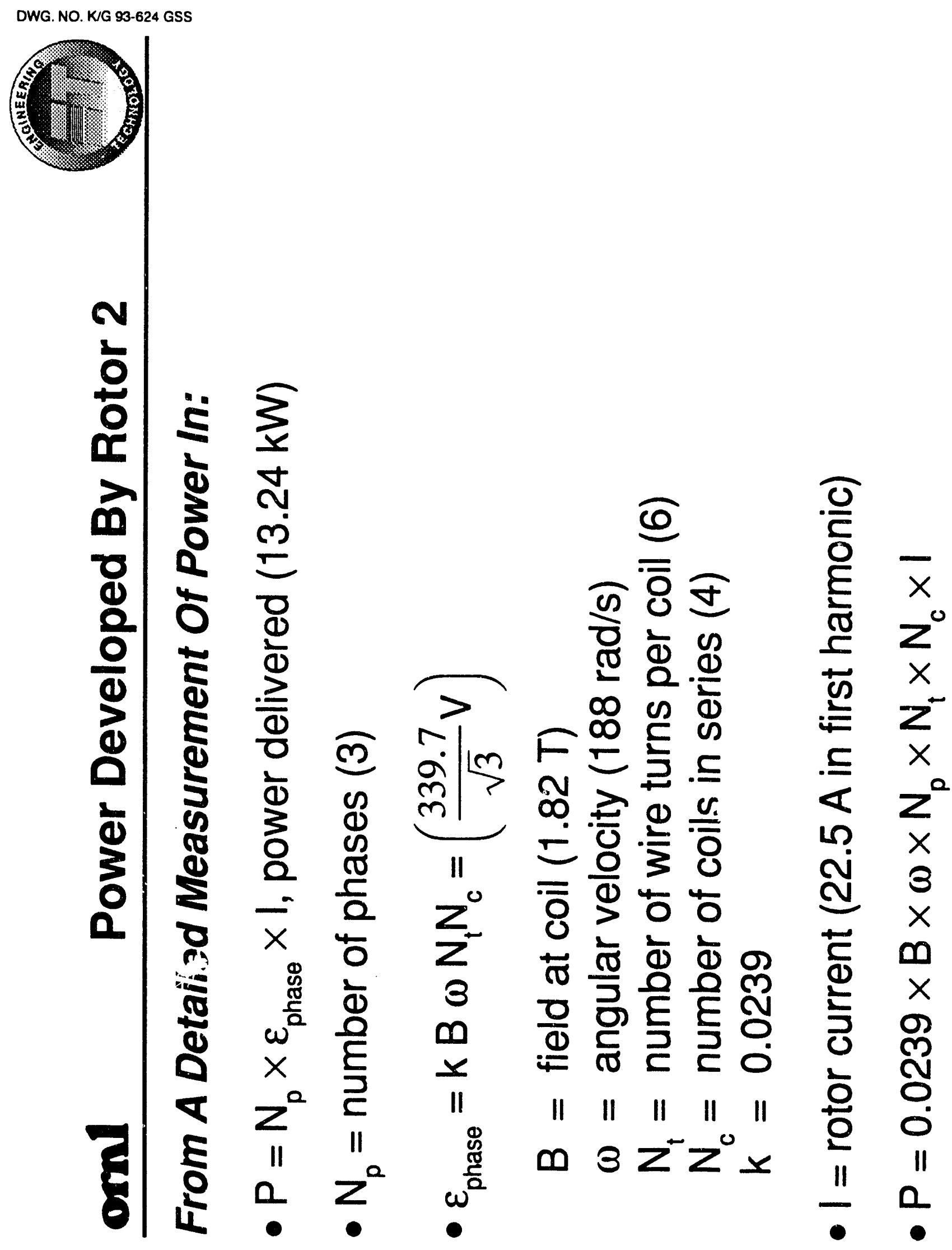


DWG. NO. KG 93-634 GSS

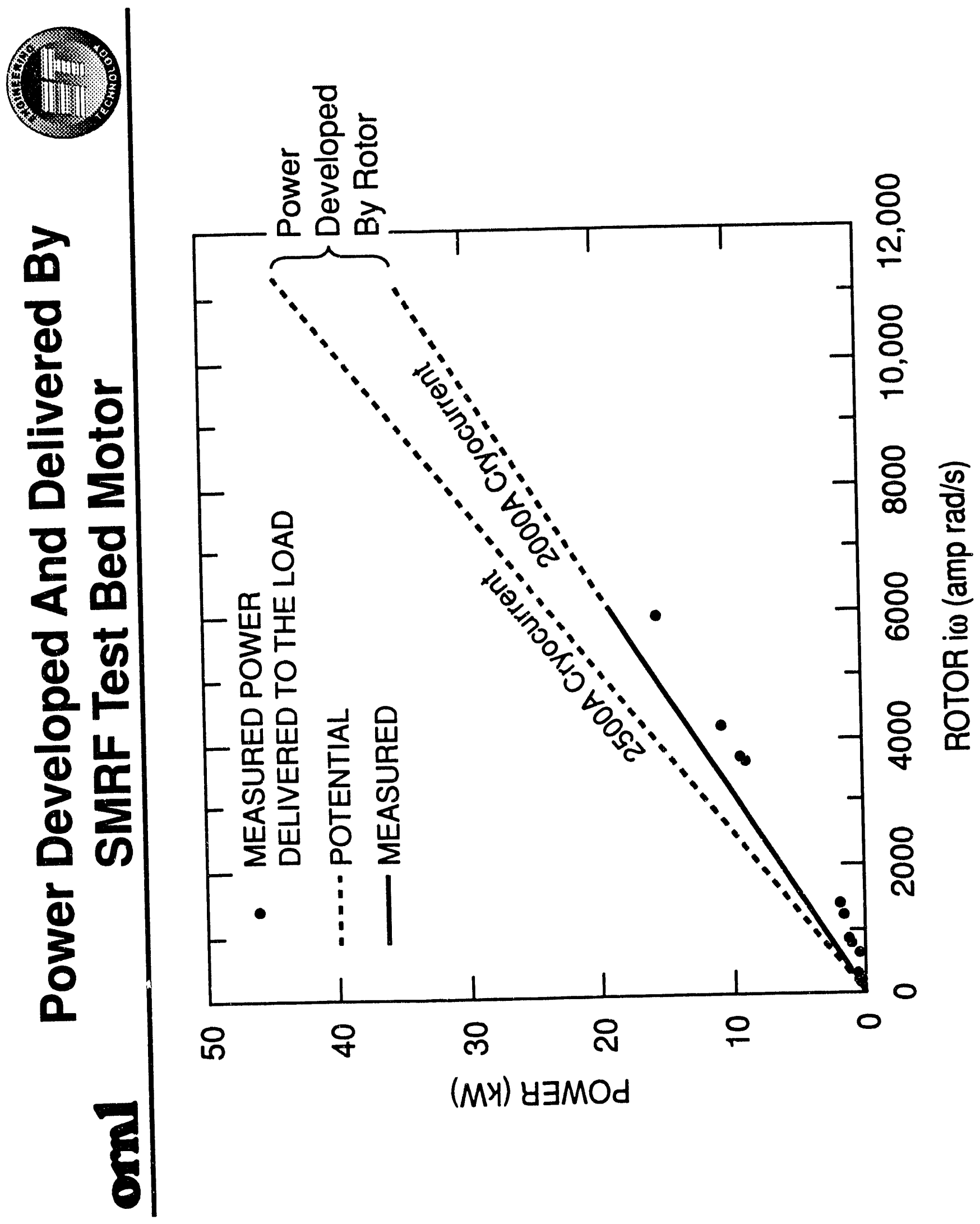


DWG. NO. K/G 93-633 GSS

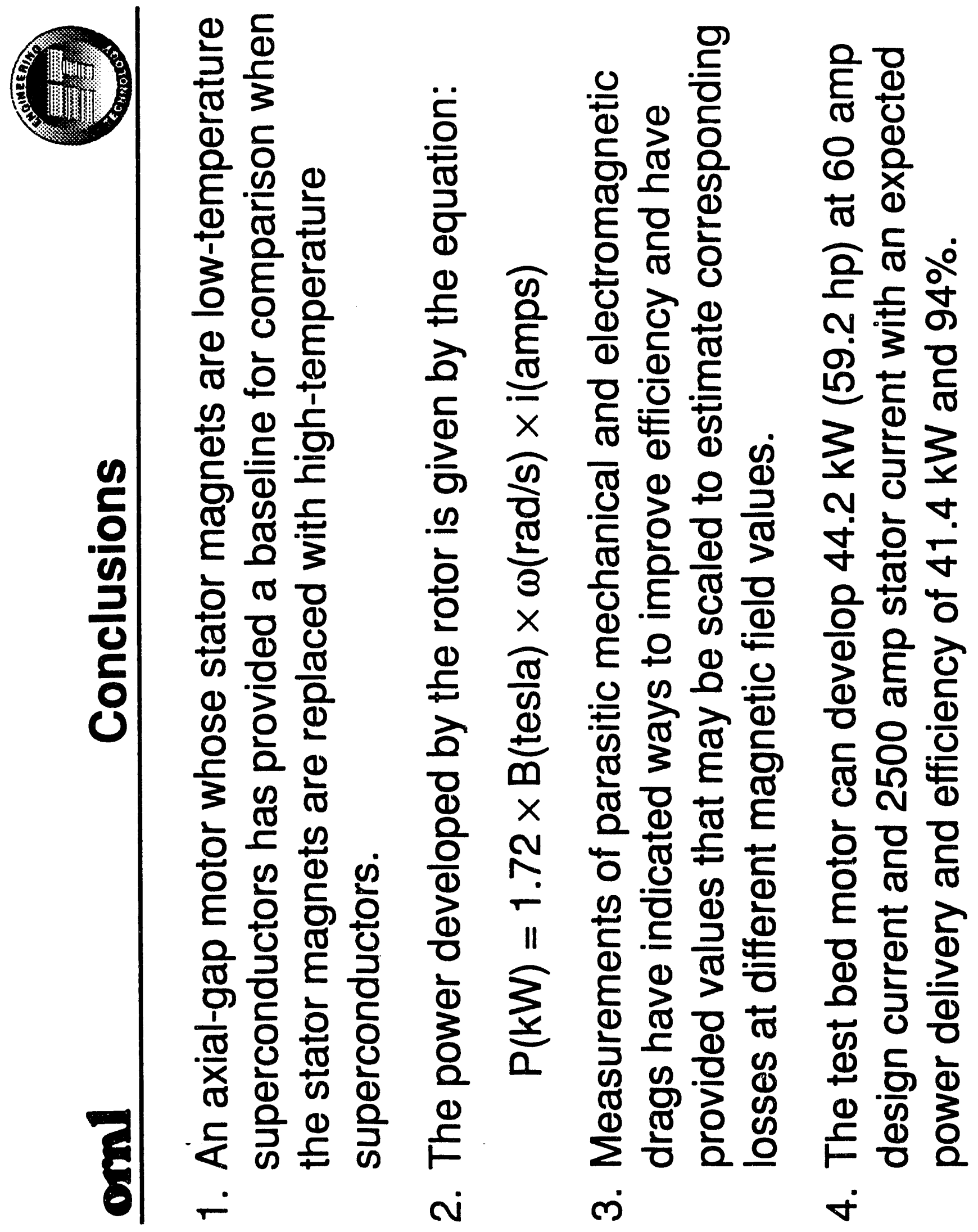


Supporttong Viewg]paphs

SMRF Proof-of-principle Team - 1990 (photo)

Fleld of Superconducting Magnets

Birdseye View of SMRF Motor Pit (photo)

Electrical Configuration of Rotor 2

Power Distribution in SMRF Test Bed Motor 
DWG. NO. KG 93.603 GSS

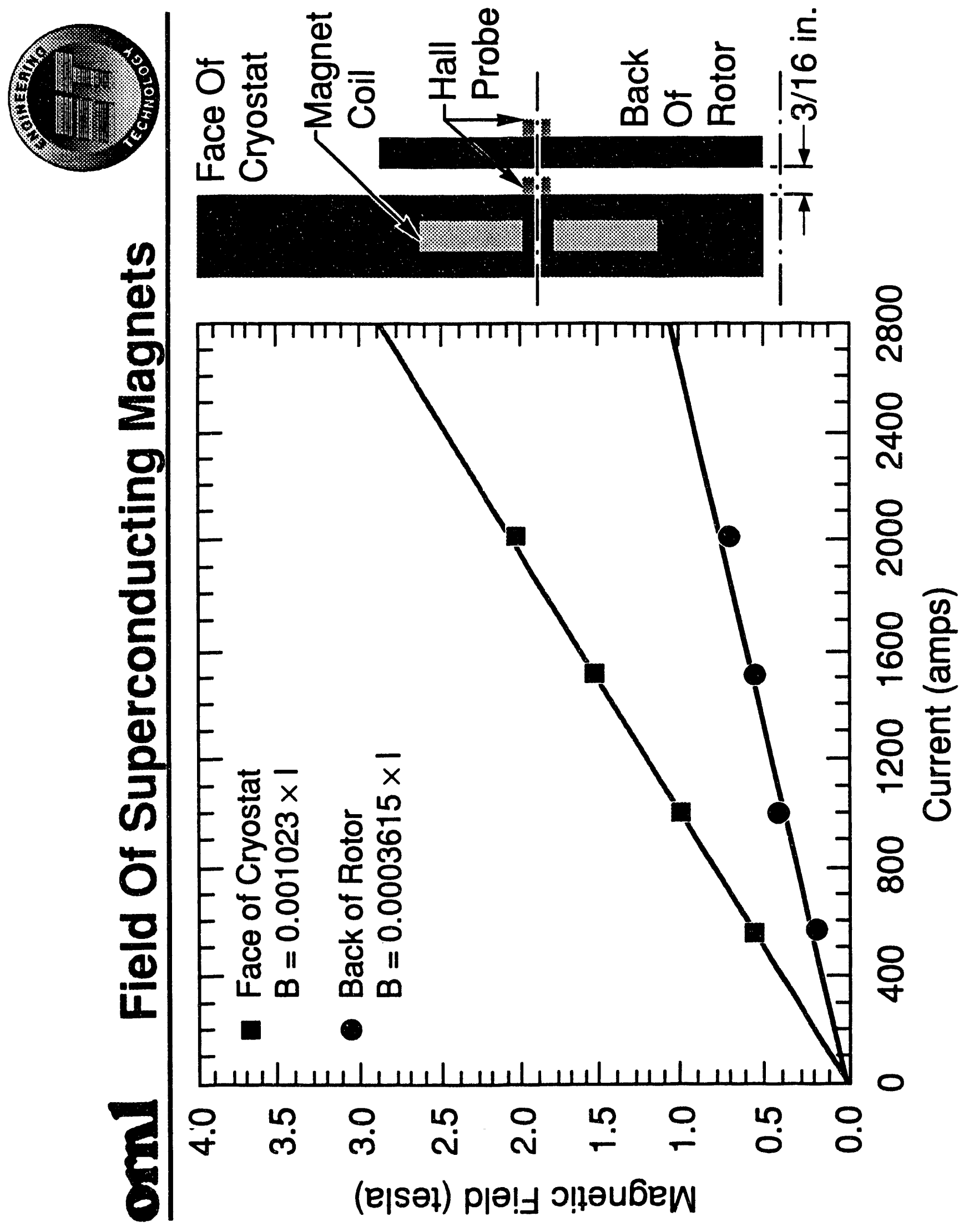


DWG. NO. KG \$3-621 GSS

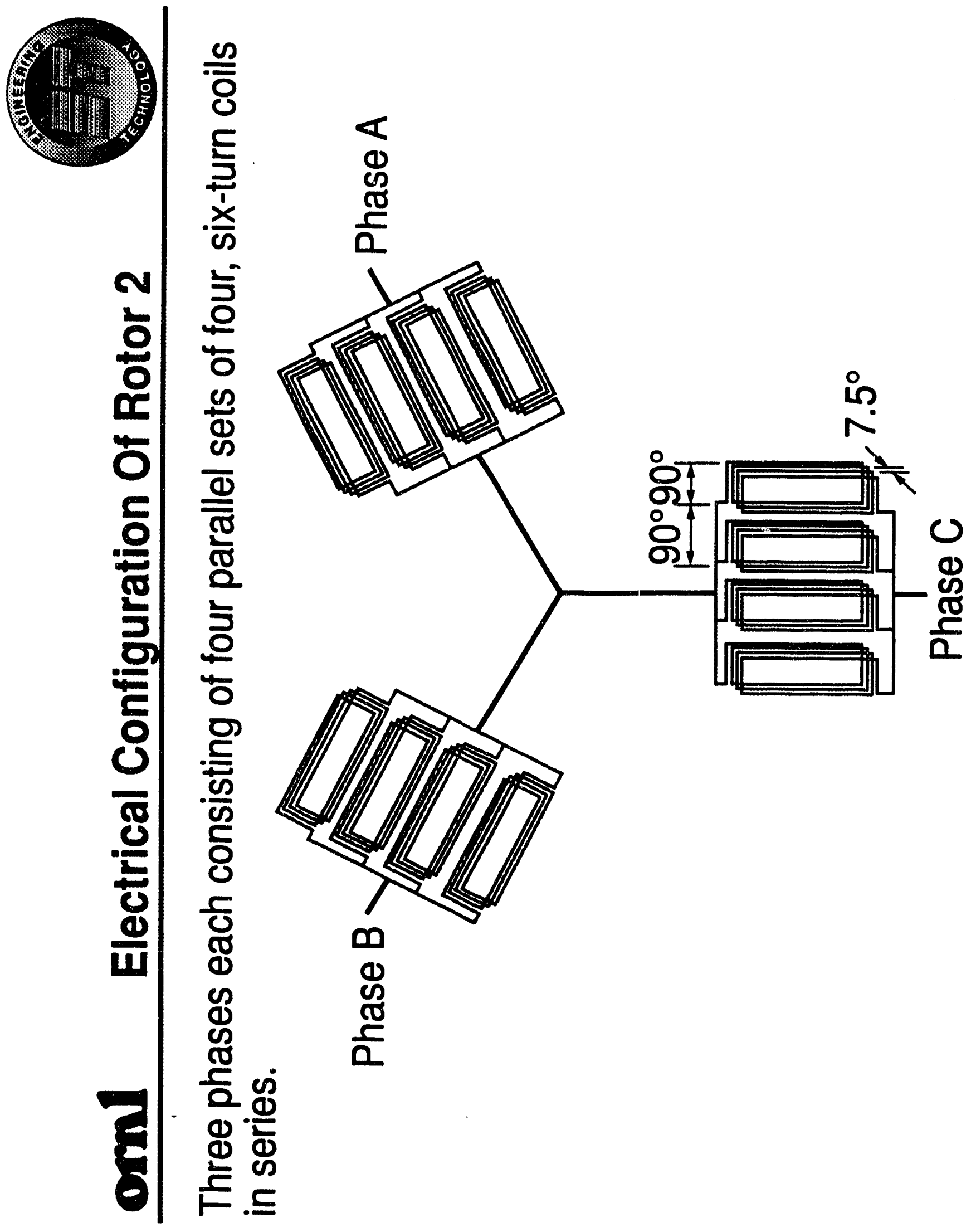


ORNL-DWG 93M-10534

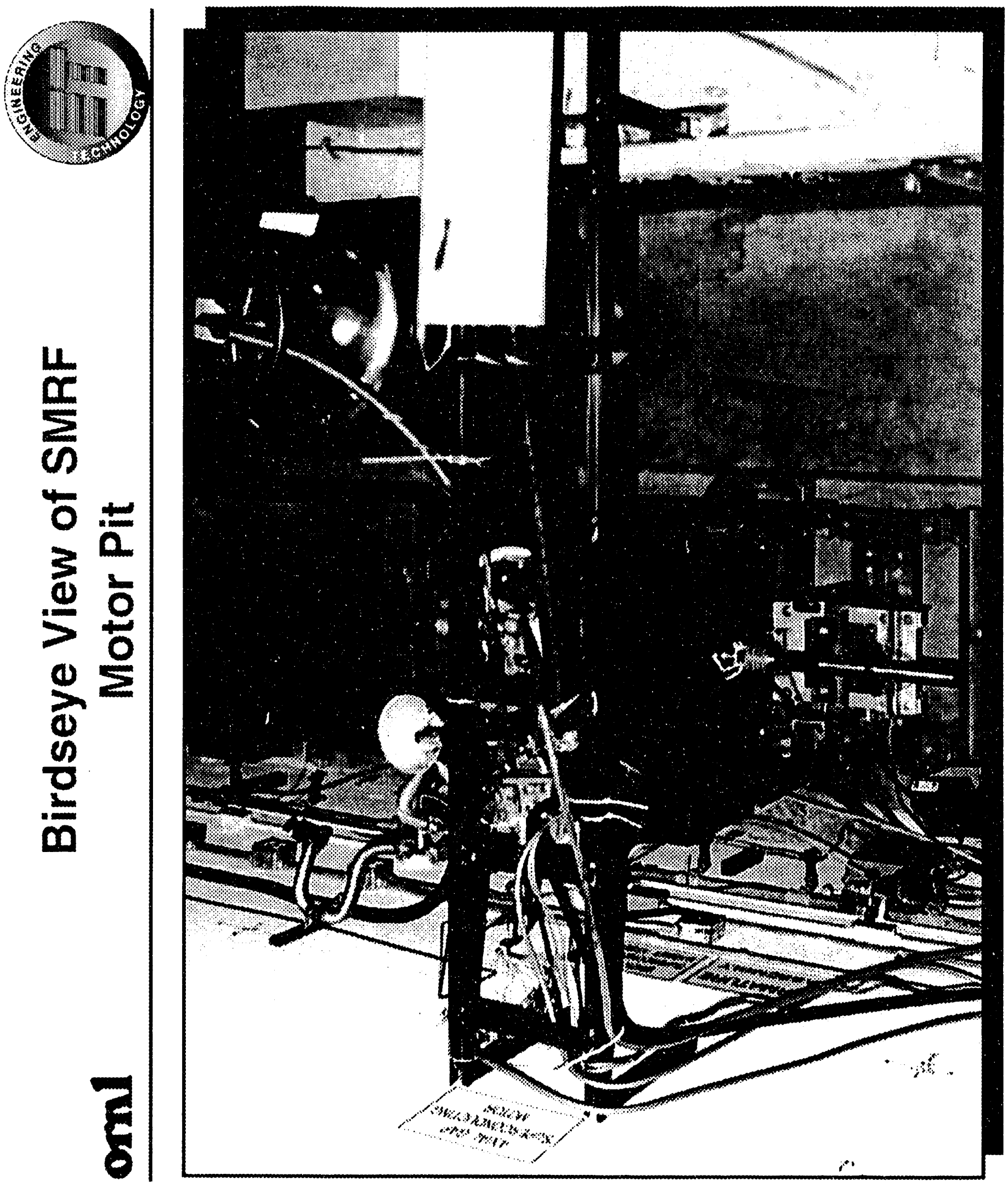


ORNL-DWG 93M-10532

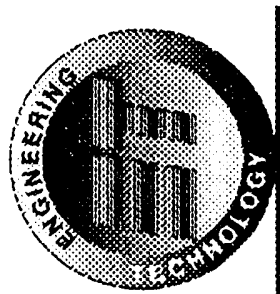

$\frac{8}{0}$

(1)

$\frac{\frac{1}{0}}{\frac{0}{0}}$

논

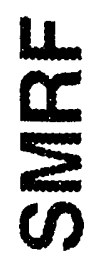

$\bar{\xi}$

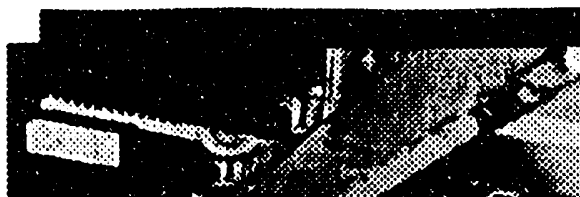

$a^{2}$

ख
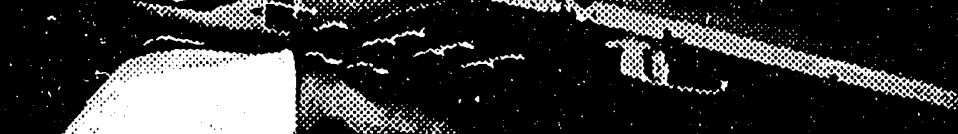

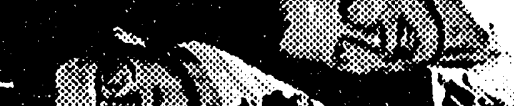

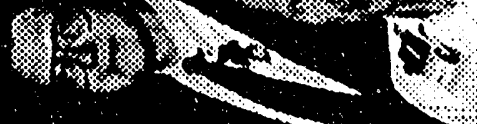

a. 8 :
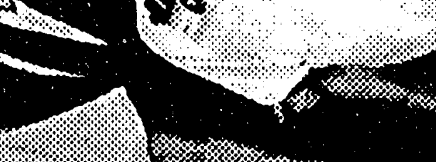

s.
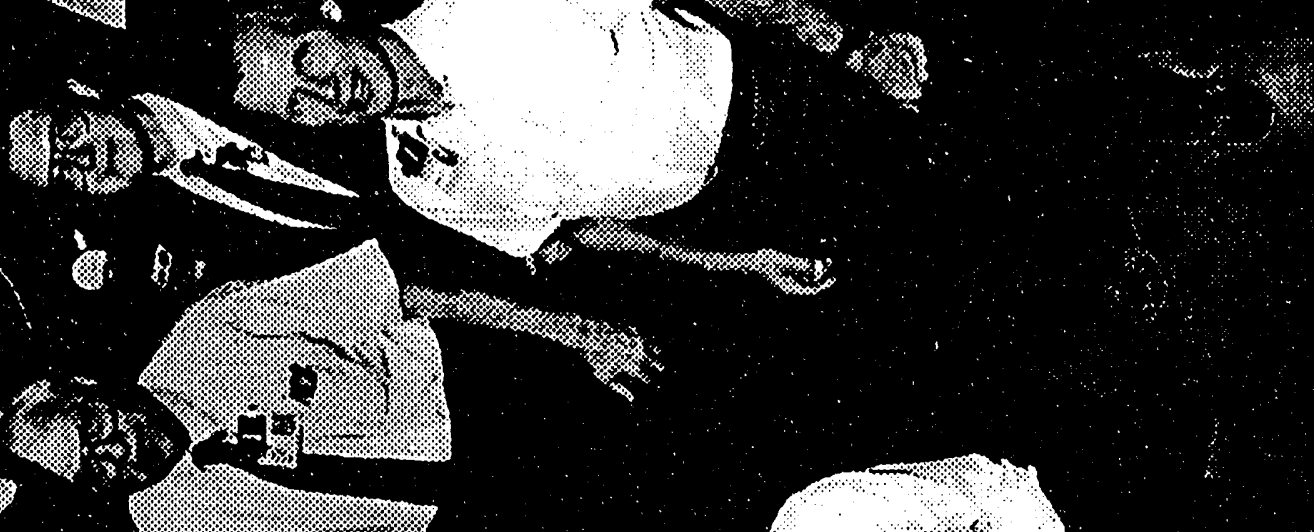

(4)

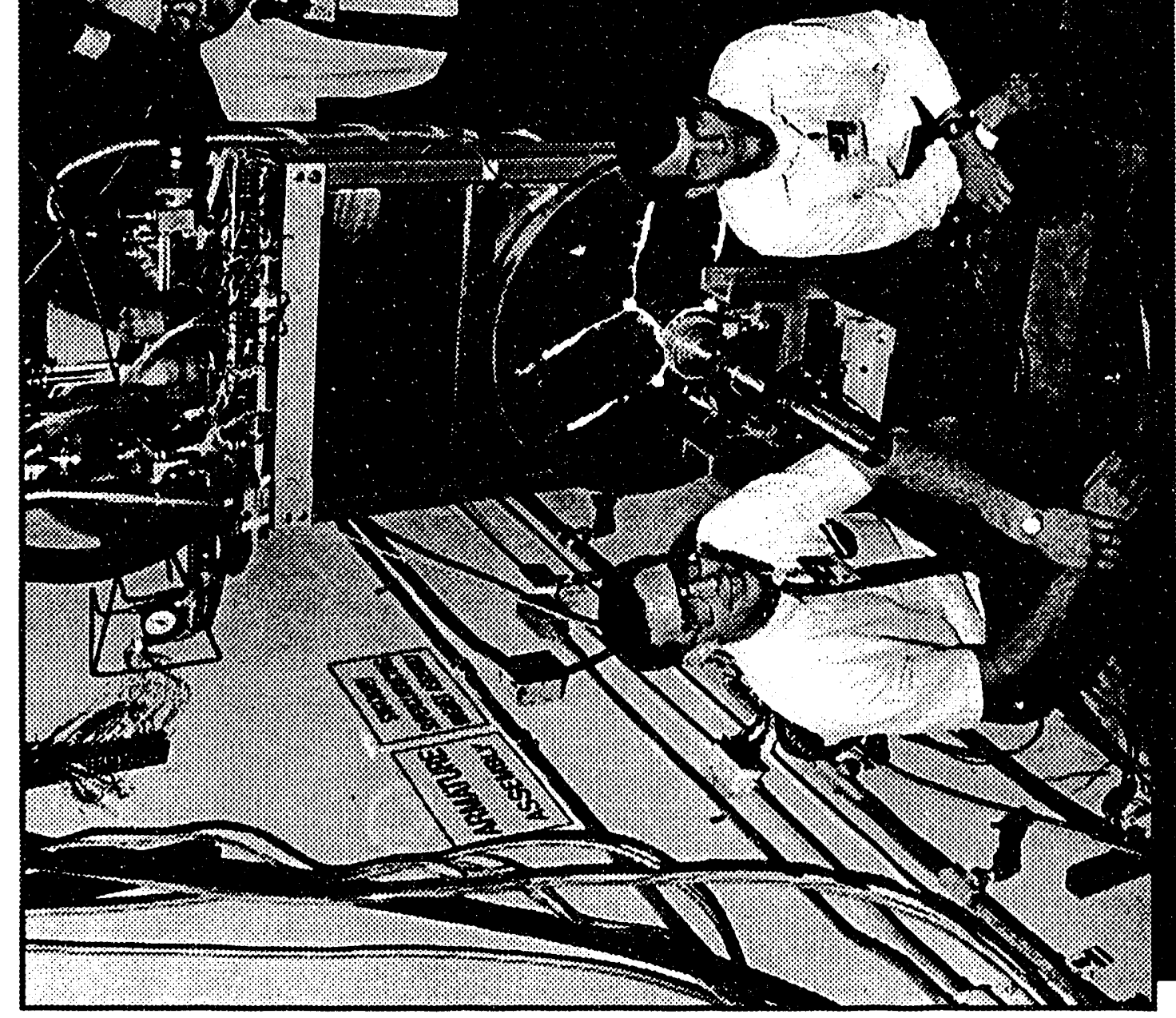




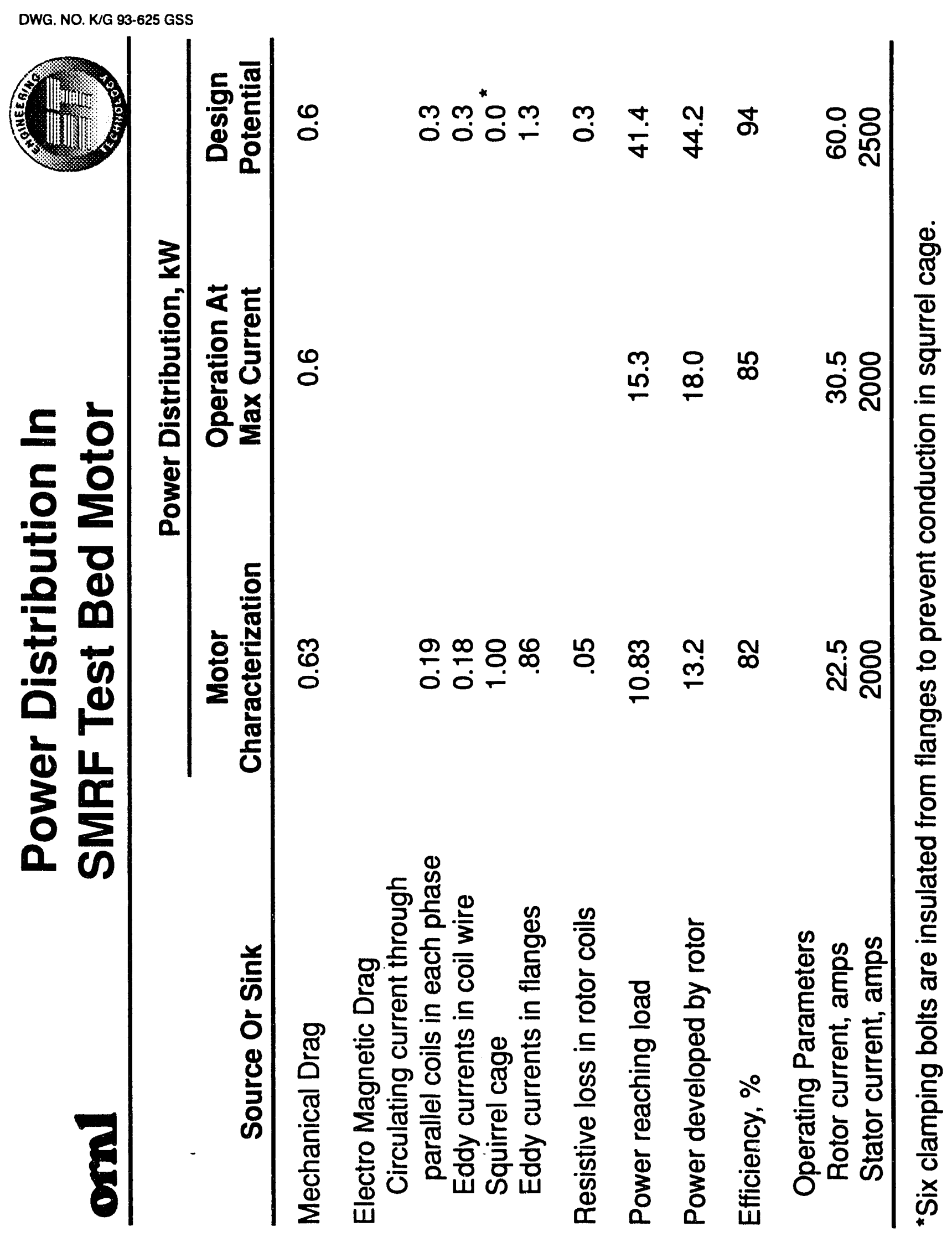



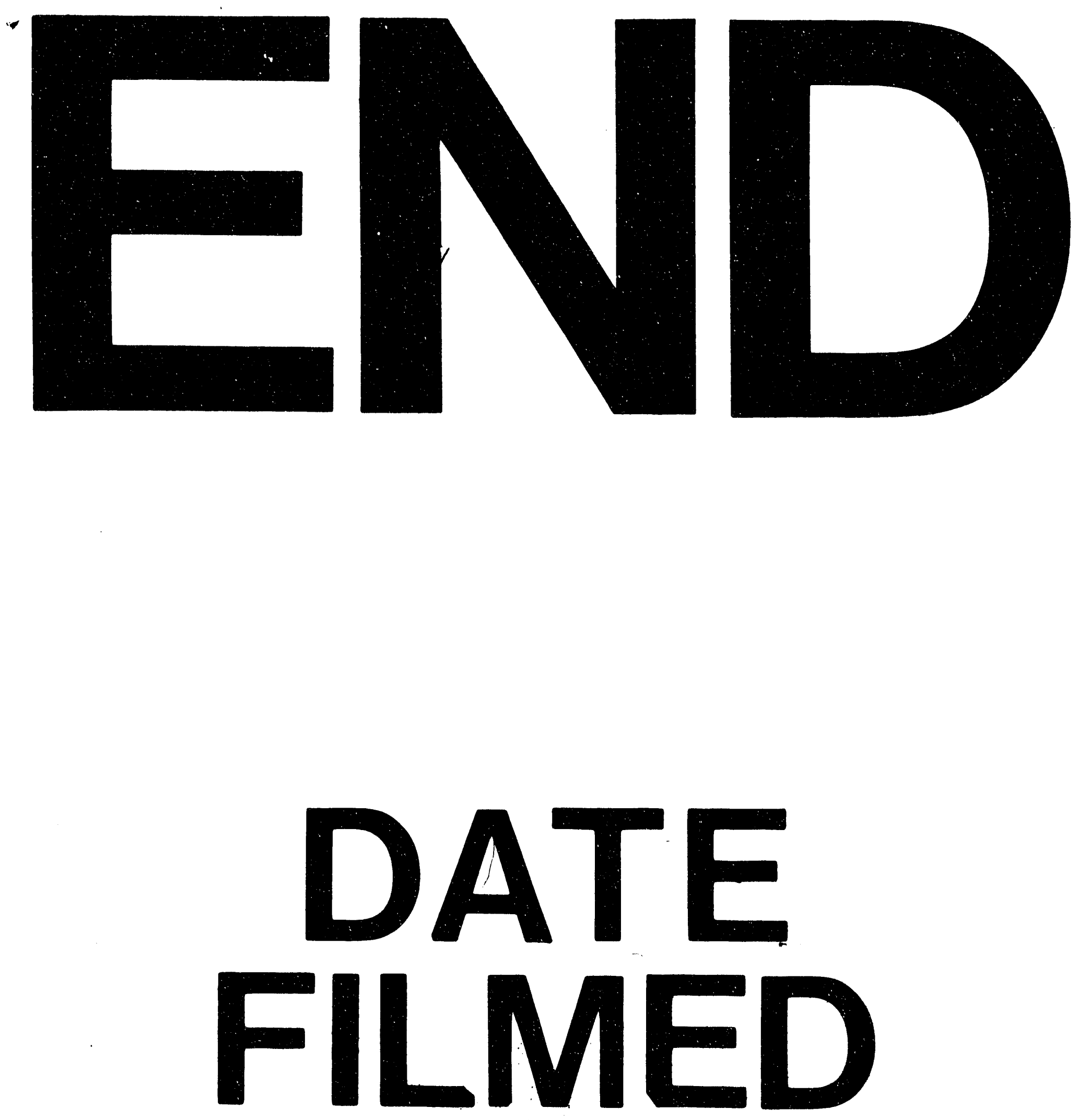

1

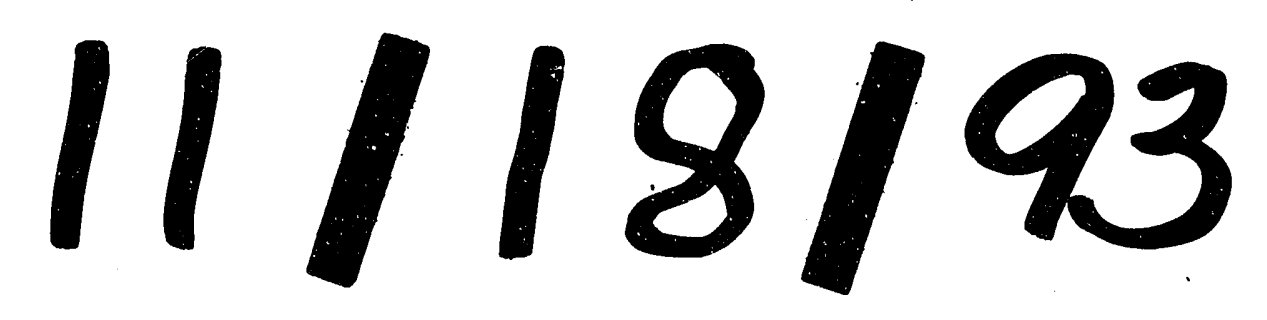


